\title{
Broker Trading Volume: A Conflict of Interest?*
}

\author{
Tiana Lehmer \\ Ben Lourie \\ Devin Shanthikumar ${ }^{\dagger}$ \\ The Paul Merage School of Business \\ University of California, Irvine
}

November 15, 2019

\begin{abstract}
Using unique new data, we examine whether brokerage trading volume creates a conflict of interest for analysts. We find that earnings forecast optimism is associated with higher brokerage volume, even controlling for forecast and analyst quality, recommendations, and target prices. However forecast accuracy is also significantly associated with higher volume. When analysts change brokerage firms, they bring trading volume with them, influencing trading volume at the new brokerage house. This indicates that analysts drive the volume effects we observe. Consistent with a reward for generating volume, brokerage houses are less likely to demote analysts who generate more volume. Finally, analysts strategically adjust forecast optimism based on expected volume impact. Analysts become more (less) optimistic if their optimistic forecasts in the prior year were more (less) successful at generating volume. However, consistent with higher costs to increasing accuracy, analysts do not update accuracy based on expected volume impact. Overall, our results are consistent with a brokerage trading volume conflict of interest moving analysts towards more optimistic earnings forecasts, despite the volume reward for accuracy.
\end{abstract}

Keywords: Sell-side analysts, brokerage houses, trading volume, commissions, conflicts of interest, incentives, earnings forecasts

JEL Codes: G24, D82, M41, M52

\footnotetext{
* We thank Mark Bradshaw, Dan Givoly, Terry Shevlin, Siew Hong Teoh, Brett Trueman, and Zhe Wang. We also thank seminar participants at London School of Economics; Washington University, St. Louis; and the University of California, Irvine, and participants and discussants at the $2^{\text {nd }}$ Cass Business School and Center for Financial Analysis and Reporting Research Conference; the American Accounting Association Annual Meeting; and the AAA Western Regional Annual Meeting.

†Ben Lourie, blourie@uci.edu; Devin Shanthikumar, dshanthi@uci.edu (corresponding author).
} 


\section{Introduction}

Sell-side security analysts play a significant role in financial markets. They provide research and investment advice to institutional and retail investors, and they contribute to firms' information environment. ${ }^{1}$ However, sell-side analysts face conflicts of interest that may cause them to bias their research output. We focus on the potential biasing of one of analysts' most salient research outputs: earnings forecasts. Historically, sell-side analyst research has been funded mainly through investment banking and through brokerage commissions (Cowen, Groysberg, and Healy, 2006). Numerous studies have documented the conflicts of interest caused by investment banking relationships, ${ }^{2}$ yet few of these studies address conflicts related to commissions. ${ }^{3}$ Prior literature has provided evidence that, across brokerage houses, more optimistic recommendations are associated with higher trading volume (see discussion of prior literature in Section 2). Whether this creates a conflict of interest for analysts, and whether and how this extends to earnings forecasts, is unclear.

Understanding the potential commissions-related conflict of interest is of particular importance given changes to the analyst research funding model. Several new rules and regulations established in the early 2000s attempted to address conflicts of interest related to investment

\footnotetext{
${ }^{1}$ See Beyer, Cohen, Lys, and Walther (2010); Bradshaw (2011); and Kothari, So, and Verdi (2016) for reviews of the literature on sell-side analysts, and Bradshaw, Ertimur and O'Brien (2017) for a more complete discussion of the history and current institutional context in which sell-side analysts operate and their role in financial markets. See also Chen, Cheng, and Lo (2010); Li and You (2015); Amiram, Owens, and Rozenbaum (2016); and Huang, Lehavy, Zang, and Zheng (2016) for more recent evidence on the roles of analysts in information discovery and interpretation.

${ }^{2}$ For research on conflicts of interest related to investment banking relationships, see, for example, Dugar and Nathan (1995); Lin and McNichols (1998); Michaely and Womack (1999); Dechow, Hutton, and Sloan (2000); and Barber, Lehavy, and Trueman (2007) for evidence on the relative optimism of investment banking-affiliated analysts versus unaffiliated analysts.

${ }^{3}$ Firth, Lin, Liu, and Xuan (2013); and Gu, Li, and Yang (2013) discuss the relative lack of research on conflicts of interest related to trading commissions. Beyer, Cohen, Lys, and Walther (2011) suggest that there is evidence that trading commissions play a significant role in optimistic recommendations but not in optimistic earnings forecasts. The primary papers examining whether analyst optimism is related to trading volume are Jackson (2005) and Irvine (2004). These papers are discussed in more detail in Section 2.2.
} 
banking. In particular, these new rules included NASD Rule 2711, NYSE Rule 472, and the Global Analyst Research Settlement. These rules aimed to separate investment banking from research, thus lowering the probability that brokers bias sell-side analyst research to gain investment banking business. Research suggests that these regulations mitigated the investment banking conflict of interest (Kadan, Madureira, Wang, and Zach, 2009; Corwin, Larocque, and Stegemoller, 2017). As a result, these changes may have increased the importance of brokerage commissions, since they are the primary remaining source of funding. ${ }^{4}$ On the other hand, "unbundling" of brokerage commissions from payment of research in Europe, as required by MiFID II, may decrease the impact of trading volume-related incentives on analyst behavior. ${ }^{5}$ The SEC is still considering what permanent changes will be made in the United States (US) in response. ${ }^{6}$

In this study, we exploit new trading volume data at the brokerage house-stock-day level, for brokerage houses operating in the US, ${ }^{7}$ to test for conflicts of interest derived from analysts' incentive to increase trading volume. We collect brokerage volume data for S\&P 1500 firms and for 18 major brokerage houses over the 5-year period of 2011-2015, and we focus on the analyst's impact on the broker's share of trading volume in a given stock. We begin by extending prior research by examining whether more optimistic analyst earnings forecasts are associated with a larger share of trading volume for the analyst's brokerage house when the forecasts are released. However, even for recommendations, prior research has not established whether a positive

\footnotetext{
${ }^{4}$ Call, Sharp, and Wong (2019) find that enforcement of these and other rules by FINRA helps to mitigate the effects of several types of conflicts of interest on analyst research. However, currently FINRA monitoring does not include the type of trading-related conflict of interest we examine in this paper.

${ }^{5}$ For more information on MiFID II, its different provisions, and implementation guidance, see the European Securities and Markets Authority page on MiFID II, https://www.esma.europa.eu/policy-rules/mifid-ii-and-mifir.

${ }^{6}$ On November 4, 2019, the SEC issued a press release that extends a no-action letter to market participants in regards to MiFID II as they evaluate the effects of the regulation (see https://www.sec.gov/news/press-release/2019-229).

${ }^{7}$ We obtain data from Bloomberg Terminal. The data are described in detail in Section 3.
} 
optimism-volume relation leads to a conflict of interest. The remainder of our paper focuses on unique new tests to better address the potential conflict of interest. Our results are consistent with trading volume creating a conflict of interest for analyst earnings forecasts.

Trading volume is likely to be increasing in analyst optimism in the short run due to shortsale costs. If investors reward a brokerage house which publishes relevant analyst research by trading through them, then that brokerage house's share of trading volume will also increase with analyst optimism. This relation could break down for two reasons. First, it is not clear whether investors will reward an analyst's brokerage firm with an increased share of trading volume immediately surrounding that analyst's research. They may trade through their normal brokerage houses, leaving the brokerage share of volume unchanged. Second, in the long run, investors may learn not to respond to analysts who are consistently biased and may instead respond more strongly to high-quality analysts. Institutional investors allocate commissions based, at least partly, on their evaluations of the usefulness of various analysts' research (see Groysberg and Healy, 2013, for an overview of relevant evidence). Industry participants argue that they use commissions to pay for high-quality analyst service (Greenwich Associates, 2015). Thus, analysts will trade off incentives to generate volume through optimistic bias with incentives to generate volume through quality.

The first step in examining the potential trading-volume conflict of interest is to examine whether optimistic earnings forecasts yield a higher share of volume for the analyst's brokerage house. Prior research has documented a correlation between analyst coverage characteristics and brokerage trading volume (e.g., Irvine, 2000; Irvine, 2004; Jackson, 2005; Cowen, Groysberg, and Healy, 2006; Agarwal and Chen, 2012; Grant, Jarnecic, and Su, 2015). Our first set of tests extends these prior papers. We find strong and consistent evidence that more positive forecasts (measured 
relative to other analysts' forecasts) increase the brokerage house's share of trading volume in the days around the forecast's publication.

We also find that several dimensions of earnings forecast quality and analyst quality increase trading volume. Specifically, the ex post accuracy of a specific earnings forecast and how early in the year the given forecast is issued (used in prior literature as a proxy for information content, see, e.g., Clement and Tse, 2003) are positively associated with the broker's share of trading volume. The analyst's prior-year forecast accuracy and firm-specific forecasting experience are also associated with a trading volume increment. Thus, based purely upon the analyst-coverage - volume relation, it is not clear whether the incentive to generate trading commissions will drive analysts to be more optimistic or to issue higher quality earnings forecasts.

The economic magnitudes of the given effects are significant. An interquartile-range increase in earnings forecast optimistic bias increases brokerage house share of trading volume by $1.1 \%$ of the mean, controlling for forecast and analyst quality effects. An interquartile-range increase in forecast accuracy is associated with an increase in volume share of $1.3 \%$ of the mean. Finally, an interquartile range increase in prior-year earnings forecast accuracy is associated with a $2.2 \%$ current-year increase in trading volume, relative to the mean, around earnings forecasts. Thus, increases in forecast optimistic bias and forecast quality both have economically large impacts on trading volume. Analyst behavior must then weigh the costs and benefits of each. For example, it is likely to require less effort to increase optimistic bias than to increase ex-post accuracy. However, forecast bias may damage an analyst's future reputation.

Having confirmed the potential conflict of interest, we conduct three additional analyses to address whether a push for volume generation induces a conflict of interest. First, we examine analyst moves to determine whether analysts have a causal effect on the brokerage share of trading 
volume. We find that when an analyst switches brokerage firms, the new brokerage house's share of trading volume around the analyst's coverage of the given stock is positively related to the volume the analyst generated at her prior brokerage house. In other words, if the analyst generated more volume at her old brokerage house, she does so at her new one as well. This suggests that analysts have a causal impact on the share of trading volume, and brokerage houses are likely to consider trading volume generation as a transferrable analyst skill.

Second, we examine analysts' career progress to observe more directly whether brokerage firms reward or penalize analysts for volume generation. We examine whether the volume share associated with a given analyst's research in a given year is associated with that analyst's career changes in the subsequent year. Since the 18 brokerage houses in our sample are all relatively large and high status, we focus on demotion, defined as moving to a smaller or lower-status brokerage house. We find that analysts who generate lower volume are significantly more likely to be demoted in the subsequent year. Thus, analysts face a strong incentive to generate trading volume.

Finally, we examine whether analysts strategically update the optimistic bias of their forecasts and/or the accuracy of their forecasts, with the goal of generating volume. If analysts are strategic about this bias, versus being honestly optimistic, we should find that analysts strategically update their biasing behavior. If a strategic analyst is more (less) successful in generating trading volume with more optimistic forecasts, then he or she should be more (less) likely to issue optimistically biased forecasts in the future. We find that optimism is increasing in prior-year optimism-volume sensitivity. This provides evidence that analysts strategically update their forecast optimism - i.e., they are more optimistic when their past experience suggests that optimism will increase their broker's share of volume. However the same would be true if analysts strategically update their accuracy to generate volume. We do not find that accuracy is increasing 
in prior-year accuracy-volume sensitivity. This is consistent with the additional resources and effort required to become more accurate in the subsequent year being too high for analysts to update accuracy. Our results do not preclude analysts improving accuracy over a longer time period, but they suggest that at least on the one-to-two year horizon, analysts are more likely to strategically update optimism than accuracy.

Ultimately, proving that an analyst is being influenced by a conflict of interest is almost impossible. Analysts' internal motivations are unobservable. Despite a large literature on investment banking conflicts of interest, the literature has had difficulty establishing whether underwriting analysts intentionally bias their research upwards, or whether firms simply choose underwriters whose analysts are optimistic about them (see, e.g., the discussion in Bradshaw 2011 and Malmendier and Shanthikumar 2014). However, understanding potential conflicts of interest is of vital importance. The existing literature on broker trading volume has described the relationship between optimism and trading volume. We take the first meaningful step in establishing that a resulting conflict of interest affects analyst behavior.

Our study contributes significantly to the literature on sell-side analysts by addressing one of the major potential conflicts of interest that analysts face. In the current analyst funding model, brokerage commissions affect almost all sell-side analysts. Thus, it is especially important to understand commission-related incentives. This contribution is particularly relevant due to the implementation of the revamped Markets in Financial Instruments Directive (MiFID II) in Europe, which requires that asset managers pay for sell-side research directly, and not through trading commissions (Financial Conduct Authority, 2017). All brokerages that distribute research to European clients fall under the new regulation (see, e.g., Engler, 2017). In this paper, we show that trading commissions currently reward analyst research for both optimism and quality. It is unclear 
what effects MiFID II will have. On the one hand, institutional investors argue that direct payments, with clearly defined fee structures, will not allow them to reward quality in the same way that the current structure allows (Greenwich Associates, 2015). On the other hand, analysts will have less motivation to bias their research optimistically if trading commissions are reduced.

Our study also contributes to the open question of why analyst earnings forecasts are optimistically biased. It has long been observed that earnings forecasts, excluding those just before the earnings announcement, are overly optimistic (O'Brien, 1988). Yet, current literature does not provide a satisfactory explanation for this observed pattern, given weak and sometimes conflicting results across studies (see Beyer et al., 2010; and Bradshaw, 2011, for surveys of explanations and existing evidence). Hong and Kubik (2003) show that analysts are rewarded for forecast optimism with career advancement, controlling for accuracy, but it is unclear why brokerage houses value optimism. Our results suggest that forecast optimism leads to a larger brokerage share of trading volume and thus provides an explanation for (US) brokers' preference for optimistic forecasts.

Overall, our results are relevant for researchers, regulators, and investors. Our results show evidence of a conflict of interest based on trading volume: an incentive to upwardly bias research. Optimism has a significant effect, despite a brokerage-volume reward for quality. Evidence of analysts becoming more or less optimistic based on past success in generating trading volume suggests that analysts are aware of this, and they are — at least in part—-strategically optimistic.

The remainder of the paper is organized as follows. Section 2 presents background information, including relevant institutional details, theory, and empirical evidence, and develops hypotheses. Section 3 describes the data and the sample used in this study. Section 4 presents results. Section 5 concludes. 


\section{Background and Hypothesis Development}

\subsection{Analyst Incentives and Institutional Details}

In practice, sell-side analyst research is primarily funded indirectly through revenues brought in by other activities of the brokerage house. While some research, particularly that of stand-alone research companies, is funded through direct payments for research, the two primary sources of funding for research in the US have been investment banking and brokerage. However, in the wake of several scandals, most notably the trial of Merrill Lynch analyst Henry Blodget, NASD Rule 2711 and the amended NYSE Rule 472, effective in 2002, required virtually all investment banks that provided sell-side analyst services to cut the ties between investment banking and analysts. These regulations limited communication between the two departments, and analysts could not be compensated based on specific investment banking business. The terms of the Global Analyst Research Settlement between the SEC, NYSE, NASD, the New York Attorney General, and 12 investment banks (published in December of 2002) required additional separation for the affected banks. These regulations likely reduced the investment banking component of analysts' compensation, increasing the relative importance of brokerage trading commissions.

Brokerage houses can increase their share of overall market trading volume in one of two ways. The first method is directly inducing customers to trade, for example, through broker calls to customers with updated investment advice. Anecdotally, this appears to be a primary method of generating trading volume with retail investment clients and smaller portfolio managers. The second method is providing a high level of service to larger institutional clients who then allocate more of their trading to the bank as a form of compensation. This is typically done through "broker votes," in which buy-side clients evaluate brokerage houses quarterly, semiannually, or annually, for the services they have provided—including analyst coverage. The resulting votes are used by 
the trading desk in the subsequent period to allocate trades across brokers (Greenwich Associates, 2015).

While analysts potentially play an important role in both methods of increasing brokerage trading commissions, their effect on broker votes is likely to be harder to measure. The lag between analyst coverage and the trade allocated to the brokerage house is likely to range from less than a quarter to over a year. The trade allocated in the subsequent period to the analyst's brokerage house could also be for any stock, not just the ones that the given analyst covered. In addition, since broker votes aggregate the evaluation of all the broker's analysts and other services, the effect of a given analyst's research becomes harder to measure.

In contrast, the effect of analyst research on inducement of trade (e.g., through brokerage calls) is much more direct. Consider the following example: An analyst issues an earnings forecast. The brokerage house's brokers call clients to relay this investment advice, and a subset of those investors trade. As a result, there is an increase in the recommending analyst's broker's share of trading volume for that stock. In our study, we focus on this aspect of trade: the immediate increase in a broker's share of trading volume around that broker's analyst research. ${ }^{8,9}$

Evidence on analyst compensation supports the premise that analysts are rewarded for generating trading volume and, in turn, for generating commissions. Cowen, Groysberg, and Healy (2006) state that brokerage houses without investment banking arms "... usually reward their

\footnotetext{
${ }^{8}$ Our research design may fail to capture the full effects of analyst research on brokerage share of trading volume, and the impacts of brokerage-volume incentives on analysts' careers and behavior. However by using a shorter window, focusing on the period during which we expect the research-volume relation to be strongest, we minimize noise and increase our power to detect a direct relation between analyst research and volume.

${ }^{9}$ The investors responding to broker calls could be retail or institutional investors. Retail investors may be unlikely to trade through multiple brokerage firms. If an individual retail investor has a TD Ameritrade account, for example, and sees that a Morgan Stanley analyst updated their recommendation, they are most likely to trade through their TD Ameritrade account. However, retail investors may trade more often when prompted by their brokerage firm to do so.
} 
research analysts using a single measure of performance: trading volume in the stocks they cover" (p. 125). According to analysts surveyed in Brown, Call, Clement, and Sharp (2015), an analyst's "standing in analyst rankings or broker votes" is one of the most important factors that affects compensation (p. 25). Forty-four percent describe "success at generating underwriting business or trading commissions" as "Very Important" to compensation (Table 8, p. 28).

\subsection{The Potential for Bias}

The literature has extensively examined the risk of investment banking conflicts of interest among equity analysts (see Beyer et al., 2010, and Bradshaw, 2011, for reviews of the literature). While the investment banking conflict of interest has garnered much attention, the actual occurrence of these conflicts is infrequent. For example, Hong and Kubik (2003) report that in their sample, only $3 \%$ of an analyst's portfolio consists of stocks that have an underwriting relationship with the analyst's brokerage house. These infrequent conflicts leave open the question of why earnings forecasts and stock recommendations are optimistically biased (Beyer et al., 2010, p. 333). Theory and intuition suggest that the incentive to generate trading volume and brokerage commissions for the brokerage house may account for part of this optimistic bias.

Beyer and Guttman (2011) develop a model in which, if analysts are rewarded based on trading volume in the stocks they cover, analysts bias their forecasts upwards, on average. In their model, investors are risk averse, with informed and uninformed strategic investors and noise traders interacting in the market. This leads to more trade for positive information than for negative information, with the exception of extremely negative news, and thus leads to the analyst's strategic biasing of research. While their model predicts that analysts will bias extremely negative news downwards, it predicts that they more frequently bias positive news upwards, leading to an 
average optimistic bias to generate trade. In reality, many investors face short sale constraints, or at least significant costs for short selling, which would further increase the asymmetry between trade generated by positive analyst research versus negative analyst research. Beyer and Guttman (2011) establish theoretically that positively biased research can generate incremental trading volume even with utility-maximizing investors, and biasing forecasts can be an optimal strategy for analysts even when they face reputational costs. ${ }^{10}$

However, investors can learn over time whether an analyst tends to bias her research upwards. Beyer and Guttman (2011) model a game in which the analyst issues a single forecast, precluding reputation building. In reality, repeated-game reputational effects might lead to a lower investor volume reaction to an analyst's future research if they bias their forecasts more heavily. This would deter analysts from biasing their research and would provide an incentive for quality.

It is particularly unclear whether analysts would be willing to bias earnings forecasts upwards relative to their willingness to bias buy/sell recommendations, given three institutional details. First, earnings forecasts are associated with clear ex post earnings realizations, which makes it evident when a forecast has low accuracy. In contrast, recommendations are not associated with a specific investment horizon, and it can be difficult to determine the correct risk adjustment when evaluating a raw return, which in turn makes it more difficult to evaluate the quality of a recommendation ex post.

Second, retail investors react more strongly to recommendations, while institutional investors react more strongly to earnings forecasts (Mikhail, Walther, and Willis, 2007;

\footnotetext{
${ }^{10}$ Hayes (1998) also models the impact of trading commissions on analyst behavior, assuming that the analyst reports truthfully. The analyst then chooses to allocate more effort to covering stocks for which positive information is likely. The end result is that the analyst is optimistic, on average, due to bias in coverage decisions and effort allocation.
} 
Malmendier and Shanthikumar, 2014). Institutional investors are more likely to be aware of analyst biases (Malmendier and Shanthikumar, 2007, 2014; Mikhail, Walther, and Willis, 2007), and they have a more direct impact on analysts' careers and reputations (e.g., institutional investors determine rankings such as Institutional Investor magazine's All Star Analysts). This increases the costs of biasing forecasts.

Third, analysts face a countervailing pressure from the management of covered firms to bias earnings forecasts downwards, making them easier to "meet or beat." As a result, analysts are more likely to issue lower earnings forecasts near the time of an earnings announcement, which generates a "walk-down" pattern in earnings announcements (Richardson, Teoh, and Wysocki, 2004). Analysts are also more likely to issue lower earnings forecasts when they face an investment banking pressure, even while they issue more positive recommendations (Baik and Yi, 2007; Malmendier and Shanthikumar, 2014), and to have a similar divergence in behavior when initiating coverage with strong buy recommendations (Ertimur, Muslu, and Zhang, 2011).

Ultimately, it is an empirical question whether optimistic or high-quality forecasts increase the share of trading volume that is channeled through an analyst's brokerage house. It is also an empirical question as to what effects these incentives have on analyst earnings forecasts.

\subsection{Prior Empirical Evidence}

There is empirical evidence that the incentive to generate trading volume is a factor in driving positive stock recommendations; however, the results for earnings forecasts are mixed, with no clear evidence that trading-volume incentives drive optimistic forecasts (Beyer et al., 2010, p. 133). Irvine (2004), using 1993-1994 Toronto Stock Exchange data, finds that buy (sell) recommendations are (are not) positively associated with trading volume. However, more 
positive/optimistic forecasts fail to generate additional trading volume. Jackson (2005), using 10 years of Australian data, shows that annual brokerage share of trading volume is increasing in the prior-year survey-based ranking of the analyst covering the stock, and in the analyst's current-year average recommendation level. However, Jackson (2005) finds mixed results for earnings forecasts, with no positive relation between 1-year-ahead forecast optimism and volume, after controlling for analyst quality. Grant and Jarnecic (2015) also use Australian data, and find a positive relation between the monthly brokerage share of trading volume and top $20 \%$ forecast optimism, but do not control for quality. Juergens and Lindsey (2009) and Neihaus and Zhang (2010) use Nasdaq data, but focus exclusively on recommendations. ${ }^{11,12}$

Overall, these studies fail to find evidence that optimistic earnings forecasts drive additional brokerage share of trading volume, after controlling for analyst quality. However these papers largely use non-US and/or pre-Global Settlement data. The US Setting differs from Canada

\footnotetext{
${ }^{11}$ Juergens and Lindsey (2009) find increased trading for recommendation upgrades and downgrades, suggesting indirectly that trading volume does not incentivize upward bias in recommendation levels. Neihaus and Zhang (2010) find a higher broker share of trading in the months in which analysts issue above-median recommendations, with increases in trading for both upgrades and downgrades.

12 Cowen, Groysberg, and Healy (2006) and Agarwal and Chen (2012) take a cross-brokerage approach to examining the impact of brokerage trading volume incentives on analyst research. Cowen, Groysberg, and Healy (2006) show that brokerage houses that lack an underwriting business (and thus presumably rely more on brokerage business) issue more optimistic earnings forecasts and recommendations. However, Agarwal and Chen (2012) directly measure the revenue breakdown for brokerage houses, and find no evidence that quarterly earnings forecasts are more optimistic for brokerage houses that depend more on brokerage business as a source of revenue. Firth, Lin, Liu and Xuan (2013) and $\mathrm{Gu}, \mathrm{Li}$, and Yang (2013), using Chinese data, find evidence consistent with analysts issuing more optimistic recommendations for stocks owned by mutual funds which pay the brokerage firm higher fees. Our focus is on tradegeneration: whether more optimistic (or higher quality) analyst research output, such as recommendations and earnings forecasts, generate higher trade for the brokerage house.
} 
and Australia in important ways. ${ }^{13}$ It is not clear that findings regarding analyst behavior documented in one of these countries extend to the others. ${ }^{14}$

Overall, the evidence from these papers is highly mixed. Most importantly, there is no clear evidence (1) that optimistic analyst earnings forecasts bring in a larger broker share of volume, particularly when controlling for forecast and analyst quality; (2) whether analysts' careers are impacted by their volume generation; and (3) whether analysts modify their behavior due to the volume-generation incentive.

Ultimately, prior evidence is mixed as to whether analyst earnings forecast optimism is associated with higher brokerage trading volume, and does not directly address whether optimismvolume relations create a conflict of interest, for either recommendations or forecasts.

\subsection{Hypotheses}

Based on the theory and evidence described in Sections 2.1, 2.2, and 2.3, we state two sets of formal hypotheses, in alternative form.

\footnotetext{
${ }^{13}$ Canada and Australia both have smaller financial markets, in terms of number of stocks actively traded, the market value of publicly traded stocks, and the number of analysts covering stocks. As of March 29, 2019, the market value of Canadian (Australian) publicly listed stocks was USD 2.4 (1.5) trillion, while the market value of US publicly traded stocks was USD 32.1 trillion (https://data.worldbank.org/indicator/CM.MKT.LCAP.CD?). The research industry is also smaller in Australia and Canada than in the US. I/B/E/S reports $10 \%(20 \%)$ as many earnings forecasts in Australia (Canada) as in the US over the 20 years from 1995 through 2014. Based upon I/B/E/S data, the average covered stock in the US has $25 \%$ higher analyst coverage than the average covered stock in Australia or Canada. In addition, both the Canadian and Australian stock markets are dominated by financial services and commodities-based industries (e.g., mining, oil and gas, other commodities) (https://www.tsx.com and https://www.asx.com/au, accessed March 2019). Earnings predictability is likely to be very different for financial services and commodities-based industries than most others.

${ }^{14}$ Using several different measures, Habib and Hossain (2008) fail to find evidence of "meet or beat" earnings management. Thus, one of the key incentives that differentiate earnings forecasts from recommendations in the US is less likely to be present in Australia. The role of the Global Settlement is also extremely important when examining broker-volume incentives. Some countries responded to the Global Settlement with changes in analyst behavior that were similar to the US, but Canadian and Australian analysts did not significantly change their behavior (Hovakimian and Saenyasiri, 2014). This suggests that the incentives for analysts in Canada and Australia differ from the incentives for analysts in the US. While the exact differences in incentives are unclear from the extant literature, it is clear that there are important differences.
} 
First, extending prior research, we expect that more optimistic earnings forecasts will lead to higher trading volume for the analyst's brokerage house around the issuance of that estimate:

H1a. More optimistic analyst earnings forecasts will lead to a larger brokerage share of trading volume for the analyst's brokerage house.

We also expect that higher-quality forecasts and forecasts from higher-quality analysts will lead to higher trading volume. We examine this directly, testing the following two hypotheses:

H1b. Higher-quality forecasts will lead to a larger brokerage share of trading volume for the analysts' brokerage house.

H1c. The forecasts of higher-quality analysts will lead to a larger brokerage share of trading volume for the analysts' brokerage house.

Finally, we jointly examine the effects of optimism, forecast quality, and analyst quality. It is an empirical question whether any one of these categories dominates.

Our second set of hypotheses addresses conflict of interest more directly. Assuming that optimistic forecasts are associated with a larger broker share of trading volume, the next question is whether the analyst drives the incremental volume. If the analyst is generating trading volume, then when she moves to another brokerage houses, we should find that the volume response at the new brokerage house changes. In particular:

H2a. When an analyst switches brokerage firms, the new brokerage house's share of trading volume around analyst coverage of the given stock is positively related to the volume the analyst generated at her prior brokerage house.

We examine analyst incentives more directly by examining career progression, testing:

H2b. Analysts who fail to generate brokerage trading volume are more likely to move to lower-tier brokerage houses.

Finally, we examine whether analysts strategically bias their earnings forecasts, or strategically improve accuracy, to generate trading volume. Intuitively, an analyst will choose a level of optimism which increases trading volume but minimizes costs such as reduced reputation. 
However, an analyst will not automatically know what the optimal level of optimism is. They will learn from experience whether to increase or decrease their level of optimism. We design a test to examine whether analysts consider trading volume generation when updating their level of optimism. If Analyst A is more successful at generating trading volume with optimistic forecasts than expected in one year, we would expect that Analyst A will place a heavier weight on optimism in trading off the expected volume generation effects of optimism and the quality and reputation costs of optimistic bias in the subsequent year, and will thus increase optimism in the subsequent year. ${ }^{15}$ Similarly, analysts will trade off the costs of more accurate forecasts - additional time, effort, research, and use of resources - with the potential benefits. We similarly examine whether an analyst's experience with the volume-generation benefit of accuracy affects their subsequent accuracy. We hypothesize:

H2c. An analyst's earnings forecast optimism (accuracy) is positively related to the volume she generated through earnings forecast optimism (accuracy) in the prior year.

\section{Data and Sample}

We obtain trading volume data from the Bloomberg Terminal database. The Terminal provides information on the total number of shares traded for each stock-day-broker, which satisfies certain data selection criteria over a 5-year period. However, the format requires manual downloading for specified stock-broker pairs. We focus on S\&P 1500 firms and select a sample of 18 brokerage houses that have a matching broker code in the Bloomberg Terminal and produce

\footnotetext{
${ }^{15}$ This learning and updating does not imply that analysts will become successively more optimistic over time. Instead, it suggests that analysts are learning over time what the "optimal" level of optimism is for themselves. This optimum may also change as their experience and reputation evolves, requiring further updating. An analyst who goes "too far" with optimistic bias should experience a decreased optimism-volume relation as investors decrease their reaction to that analyst's overly optimistic forecasts. The analyst would then reduce optimism in the subsequent year.
} 
the highest number of recommendations in $\mathrm{I} / \mathrm{B} / \mathrm{E} / \mathrm{S}$ for the $\mathrm{S} \& \mathrm{P} 1500$ firms. The inclusion of 18 brokerage houses ensures that we examine both "bulge bracket" firms (i.e., the largest investment banks) and non-bulge firms.

We obtain data for all 18 brokerage houses for the five years from 2011-2015, covering 1,436 firms from the S\&P 1500 list that have matching Bloomberg tickers and matching Compustat and CRSP identification codes. ${ }^{16} \mathrm{We}$ obtain analyst 1-year-ahead earnings per share (EPS) forecasts, price targets, and recommendation data from $\mathrm{I} / \mathrm{B} / \mathrm{E} / \mathrm{S}$, using unadjusted files and adjusting for share splits, as appropriate, as well as stock price data from CRSP and firm characteristics from Compustat. There is a total of 179,417 analyst-firm-day observations that have a 1-year-ahead earnings forecast and all other required data.

Table 1 shows descriptive statistics related to the 18 brokerages included in our sample, which cover a wide range in terms of brokerage trading activity, analyst employment and coverage, and investment banking activity. Panel A focuses on brokerage trading volume. The mean number of shares traded by a given brokerage ranges from 2.56 million to 3.76 billion shares. Panel B provides summary statistics on the number of analysts who are employed each year by the brokerage house and who provide 1-year-ahead EPS forecasts.

Our sample selection methodology biases our sample towards brokerage houses that provide higher levels of overall analyst coverage. However, there is still significant variation in the size of brokerage houses' sell-side research departments (Brokerage Size) included in our sample. The mean number of analysts at each brokerage ranges from 49 to 236 analysts, and the average number of stocks followed by the average analyst at each firm ranges from 6 to 17 .

\footnotetext{
${ }^{16}$ Bloomberg provides only five years of data at any given time. We were unable to obtain data earlier than 2011.
} 
Finally, Table 1 Panel C provides the ratio of the number of shares traded through the given brokerage to the total brokerage net revenue for each year. The mean annual number of sample shares traded per dollar of revenue for each brokerage house ranges from 0.002 to 0.177 for the brokerages with non-missing revenue. ${ }^{17}$ Overall, our sample includes a wide range of brokerage houses that produce analyst research, although our sample is weighted towards larger firms. Our sample, by construction, excludes independent research firms.

Table 2 provides descriptive statistics for the variables used in our tests (Panel A) and correlations between these variables (Panel B). The dependent variable used in our tests, Volume Share, is the total number of shares traded in a given stock through the brokerage house over the $[-1,5]$ day window, divided by the total number of shares traded in the given stock during the window, where day 0 is the day on which an analyst issues an earnings forecast. We include day -1 , given the evidence in Juergens and Lindsey (2009) that analysts release reports to some customers before the official $\mathrm{I} / \mathrm{B} / \mathrm{E} / \mathrm{S}$ estimate date; however, results are qualitatively similar using alternate windows $[0,1]$ and $[0,10]$. Volume Share ranges from $0.005 \%$ to $25.21 \%$, with a mean of $5.31 \%$ of shares traded in a firm by a particular brokerage over the 7-day window of interest.

Optimism variables include Forecast Bias, Buy, Sell, and Target Optimism. The variable Forecast Bias is the rank (by deciles, scaled from 0 to 1) of the difference between the 1 -yearahead earnings forecast, in earnings per share (EPS), and the actual value of EPS, normalized by the fiscal year-end share price. Higher Forecast Bias indicates a higher earnings forecast relative to other analysts who have issued forecasts for the same firm at the same time. The variable Buy

\footnotetext{
${ }^{17} \mathrm{We}$ were able to hand-collect revenue data for 17 out of the 18 brokerage houses. One of the privately owned brokerages in our sample did not provide revenue information in company statements or on the company website.
} 
(Sell) is an indicator variable that takes the value 1 if the analyst issued a buy or strong buy (sell or strong sell) recommendation, and 0 otherwise. The variable Target Optimism is a ranked variable, ranging between 0 and 1 , of the newly issued price target with a horizon equal to 12 months, normalized by the prior trading day's stock price. To avoid small denominators, we require that the stock price is greater than or equal to USD 5.

The forecast quality variables used in our analyses include Current Accuracy, Herding, First, and Forecast Age. The variable Current Accuracy captures the relative accuracy of the forecast, following the ranking method of Hong and Kubik (2003) and the benchmark periods of Cowen, Groysberg, and Healy (2006). The variable Herding is an indicator variable that takes the value 1 if a forecast falls between the analyst's prior forecast and the consensus forecast, and 0 otherwise. A herding forecast is likely to convey less new information to the market, and thus will have lower value (Gleason and Lee, 2003; Clement and Tse, 2005). The variable First is an indicator variable denoting the first forecast made by a particular analyst after the prior annual earnings announcement, and Forecast Age is the number of days before the next earnings announcement date that the forecast was made, divided by 365. Earlier forecasts (First $=1$ and a higher Forecast Age) are likely to have higher value (Clement and Tse, 2003).

The analyst quality variables include Prior Accuracy, \# Forecasts, \# Years Followed, \# Firms Followed, and \# Analysts Following. The variable Prior Accuracy is defined similarly to Current Accuracy, but Prior Accuracy uses the latest forecast made by the analyst in the $[-90,0]$ day window before the prior earnings announcement. The variables \# Forecasts, \# Years Followed, and \# Firms Followed are relative-rank measures for the number of forecasts an analyst has made in the prior firm year, the number of years the analyst has followed the firm, and the number of firms the analyst follows in a given year, respectively. These variables are normalized to range 
from 0 to 1 , calculated on a stock-year basis as the value for the given analyst minus the minimum for all analysts, divided by the maximum minus the minimum for all analysts. All three are positive indicators of analyst quality. Higher \# Forecasts indicates an analyst who is more active in updating research for the firm. Higher \# Years Followed indicates more firm-specific experience. Last, \# Firms Followed is a positive indicator of analyst quality, since covering more firms is likely to develop greater industry expertise (Leone and $\mathrm{Wu}, 2007) .{ }^{18} \mathrm{We}$ also include \# Analysts Following, the total number of analysts who follow a firm in a given year, although it is not clear which directional effect to predict for \# Analysts Following. ${ }^{19}$

Table 2 Panel B reports correlations between the main variables. These correlations suggest that the variables capture distinct dimensions of optimism, forecast quality, and analyst quality.

\section{Results}

\subsection{Analyst and forecast characteristic effects on trading volume}

To assess whether analyst optimism affects the share of the total volume traded by the brokerage at the time of the analyst forecast, we estimate the following regression:

$$
\text { Volume Share }_{i j t}=a_{0}+a_{1} \text { Optimism }_{i j t}+a_{2} \text { Quality }_{i j t}+a_{3} \text { Analyst Quality }_{i j t}+e_{i j t} \text {, }
$$

\footnotetext{
${ }^{18}$ If our sample included very small brokerage houses and independent research firms, high \# Firms Followed could be an indication of a firm that has few resources and is forced to stretch analysts into covering more firms. However, for our sample of larger banks, we find that the most experienced analysts cover the most firms. The correlation between experience and \# Firms Followed is a statistically significant 0.1804, which is consistent with more experienced, more senior, and more respected analysts covering more firms.

${ }^{19}$ It may be the case that a firm followed by fewer analysts has less public information available. For such a firm, an individual analyst's forecasts are likely to have higher value. Conversely, it may be the case that higher analyst following indicates more investor interest in the firm, thus analyst research is valuable to more investors and is more likely to drive incremental trading. Thus, we make no directional prediction for \# Analysts Following, but we include it as a firm-analyst-year attribute that is likely to impact the incremental volume associated with an individual analyst's research.
} 
for analyst $i$, covered firm $j$, at time $t$; where Optimism includes Forecast Bias, Buy, Sell, and Target Optimism; Quality includes Current Accuracy, Herding, First, and Forecast Age; and Analyst Quality includes Prior Accuracy, \# Forecasts, \# Years Followed, \# Firms Followed, and \# Analysts Following. We include all earnings forecast dates. Thus, $a_{0}$ captures the effect analysts have on Volume Share purely from issuing a forecast.

We include year fixed effects, brokerage fixed effects, and firm fixed effects in the model to control for time, brokerage, and firm effects on volume share. In particular, we might expect the brokerage share of trading volume to shift over time with consolidation in the industry. If there are also time trends in analyst behavior, we might erroneously find a relation between the two if we fail to control for year fixed effects. Brokerage firm fixed effects control for the overall size and market share of each brokerage firm, as well as other brokerage-specific characteristics such as resources, accuracy, or the number of analysts; which impact both analyst behavior and the broker share of trading volume. ${ }^{20}$ Finally, we include firm fixed effects (for the covered firm). Analysts compete with each other for volume in a given firm. Our use of brokerage share of trading volume, and our relative optimism variables helps to address this, but this may not fully adjust for firmspecific effects. We also allow for arbitrary within-firm correlations in standard errors. ${ }^{21}$

\footnotetext{
${ }^{20}$ In particular, there may be style differences which affect both analyst behavior and trading volume, but these are not due to analyst behavior driving trading volume (e.g., brokerage firm culture, client type, communication style), which is difficult to measure. Cowen, Groysberg, and Healy (2006) state in their conclusion that brokerage house status and reputation likely explain some of the differences in optimism observed across brokerages in their sample. They also point out that analysts' decisions to stop covering, rather than issuing more negative coverage, may differ systematically across brokerage houses. Including brokerage firm fixed effects allows us to control for this type of difference between brokerage houses.

${ }^{21}$ In addition to these fixed effects, we control for the informativeness of earnings forecasts when examining the relation between optimistic bias and volume share by including forecast and analyst quality variables together with optimism variables. We also test the robustness of our results to two other variables which may impact the informativeness of the forecast, but which do not capture forecast quality per se. In particular, first, a new forecast may be more informative to the market, and lead to higher overall trading volume (though not necessarily brokerage
} 
The results are presented in Table 3 . We find that, in Column 1, Volume Share is positively and significantly related to Forecast Bias (coefficient $=0.069, p$-value $<0.05$ ). An increase in Forecast Bias of 0.5, which is an increase from the 25 th to the 75 th percentile of the ranked variable, is associated with an increase in volume share of $0.035 \%$ of the shares traded. This is $0.65 \%$ of the average forecast-window volume share. For a stock that has an average forecast estimate-window trading volume, this is an additional 6,194 shares traded over the 7-day window for an individual forecast.

While additional assumptions are required to convert this to trading commissions, doing so can be a useful exercise to quantify the potential incentive towards optimistic bias. With a typical commission of USD 0.03 per share traded (Levine, 2015), the additional 6,194 shares result in an increase in commission of USD 186. While the per-forecast effect appears relatively small, the overall incentive can be large, given the frequency of forecast revisions. Multiplied by the number of forecasts $(179,417)$, the potential incentive to increase forecast optimism by the interquartile range amounts to over USD 33 million, with all else equal. ${ }^{22}$

share of trading volume) if there are higher differences of opinion for the stock. In additional tests, we include an additional control variable for forecast dispersion to capture differences of opinion. We find an insignificant negative coefficient on forecast dispersion, and find that results reported in Table 3 remain qualitatively similar. Second, investment banking relationships can increase both the potential informativeness of the analyst's forecast to the market, and the market's perception of analyst bias. To examine whether investment banking relationships have a significant impact on our results, we focus on the subset of forecasts for which investment banking relationships are unlikely. We restrict to the subsample of brokerage houses with little or no investment banking business. The results reported in Table 3 remain qualitatively similar.

${ }^{22}$ Earlier papers use larger per-share or percentage commissions to estimate economic significance. Jeurgens and Lindsey (2009) cite commission rates ranging from USD 0.05 to USD 0.91 per share. Jackson (2005) uses a percentage commission that would amount to USD 0.075 per share for a stock trading at USD 50 per share. Applying the alternate commission rates used in Jeurgens and Lindsey (2009) to the results in Table 3, USD 0.05 per share implies a perforecast effect of USD 310, and USD 0.91 per share implies a per-forecast effect of USD 5,637. 
We find the expected coefficients on the control variables for recommendation and target price optimism. Buy (sell) recommendations are positively (not) related to the broker share of volume (coefficient $=0.248, p$-value $<0.001$ for buy) and Target Optimism is positively and significantly related to Volume Share (coefficient $=0.148, p$-value $<0.01) .{ }^{23,24}$ The combined effects of the intercept and slope terms imply that earnings forecasts with concurrent sell and hold (buy) recommendations experience lower (higher) Volume Share than earnings forecasts not associated with a concurrent recommendation. Similarly, earnings forecasts associated with pessimistic (optimistic) target price forecasts experience lower (higher) Volume Share than those which are not associated with concurrent target price forecast.

Table 3 Column 2 presents the results for earnings forecast Quality. We find no significant relation between First and Volume Share. However Current Accuracy, Herding, and Forecast Age are significantly associated with Volume Share, in the expected directions. Column 3 presents the results for the effect of Analyst Quality. As expected, the analyst Prior Accuracy and \# Years Followed are positively associated with Volume Share (coefficient $=0.196, p$-value $<0.01$ and coefficient $=0.211, p$-value $<0.05$, respectively). The variable \# Analysts Following is negatively related to Volume Share (coefficient $=-0.009, p$-value $<0.1$ ). However, we find no association between \# Forecasts and \# Firms Followed with Volume Share.

\footnotetext{
${ }^{23}$ Given evidence in Juergens and Lindsay (2009) that downgrades are leaked to clients several days before the recommendation becomes public, we also examine the robustness of the optimism-volume relation using a wider window for Volume Share. Results for Forecast Bias are similar for [-3, 5], focusing more directly on the pre-forecast period, $[-3,-1]$, or including both the pre-period and the immediate forecast window, $[-3,1]$.

${ }^{24}$ In additional analyses, we examine whether recent news events affect the bias-volume relation. We focus on the subset of earnings forecasts made in the five days following an earnings announcement, and partition based upon whether the earnings announcement is positive or negative, using both the earnings forecast error and the announcement-window 3-day return. We find significantly positive coefficients on Forecast Bias in three of the four subsamples, with no significant differences in coefficient between positive and negative news. Thus, preceding news does not appear to significantly impact the bias-volume relation. Conversely, we examine earnings forecasts which are isolated from other forecasts, suggesting no significant recent news has been released. Results are robust.
} 
Table 3 Column 4 presents the results, including optimism, forecast quality, and analyst quality in the same model. The results are relatively unchanged. We continue to find evidence that earnings forecast optimism leads to a larger brokerage share of volume, even after controlling for forecast and analyst quality. Similarly, quality is associated with volume, controlling for optimism. Volume Share is positively and significantly related to Forecast Bias, Current Accuracy, Forecast Age, Prior Accuracy, and \# of Years Followed; and it is negatively and significantly related to \# Analysts Following. ${ }^{25}$ These results provide evidence consistent with H1. They are also robust to a large set of additional robustness tests. ${ }^{26,27,28}$ Thus, we find a forecast-volume relation which provides a potential incentive towards optimistic bias as well as evidence of a potential incentive towards quality. In the remainder of Section 4, we report additional tests to more directly address

\footnotetext{
${ }^{25}$ The effect of an interquartile-range increase in forecast bias is an increase in broker share of trading volume of $1.1 \%$ of the mean. Interquartile-range changes in forecast and analyst quality measures have similar or higher economic significance magnitudes, with the following: forecast accuracy, $1.3 \%$, forecast age, $1.0 \%$, prior-year forecast accuracy, $2.2 \%$, analyst stock-specific experience, $2.0 \%$, and number of analysts covering the firm, $-2.3 \%$, of mean broker share of trading volume.

${ }^{26}$ The results in Table 3 show that within-broker variation in analyst forecast quality is related to variation in the broker's share of trading volume surrounding the analyst's forecast. We replicate Table 3, including analyst fixed effects rather than broker fixed effects, to examine within-analyst variation in forecast quality. We find similar results. All coefficients remain statistically significant at the $10 \%$ level or better, with magnitudes ranging from $85 \%$ to $115 \%$ of those reported in Table 3. Thus, the results reported in Table 3 and in Section 4.1 are robust to including analyst fixed effects.

We also estimate Table 3 including only year and firm fixed effects (i.e., excluding both broker and analyst fixed effects). This better captures whether more optimistic analyst research is related cross-sectionally to a larger broker share of volume. Consistent with Jackson (2005), when not including brokerage fixed effects, we include an additional control variable for total brokerage firm volume in the given year, to adjust for the overall brokerage firm market share of trading. We find similar results.

${ }^{27}$ The results presented in Table 3 are robust to estimation using a fractional logit model instead of an ordinary least squares model. Focusing on Column 4, all coefficients on optimism and quality variables that are significant at the $10 \%$ level or better remain significant using a fractional logit model, while no other coefficients are significant with the fractional logit. Thus, the results are robust to estimation using a fractional logit model.

${ }^{28}$ If forecasts cluster together in time, they may be associated with lower brokerage share of trading volume due to increased competition for volume during these forecast-cluster windows. We examine whether clustering has an impact on our results in two ways. First, we examine whether forecast optimism is a function of whether other forecasts occur during the $[-5,5]$ window, or a wider $[-10,10]$ window, surrounding the given forecast. We find no relation. Second, we replicate our main Table 3 tests including an indicator for whether the forecast is isolated. We find similar results when including an additional control variable for whether there are other forecasts in the $[-5,5]$ or $[-10,10]$ window surrounding the given forecast.
} 
whether analysts have volume-related incentives to optimistically bias forecasts or to increase accuracy.

\subsection{Trading volume following an analyst's move between brokerage houses}

The results presented above show that analyst forecast optimism and accuracy are associated with a larger broker share of trading volume. However, as with prior research for analyst recommendations, this does not establish a causal relationship between the analyst's research and trading. To address whether the analyst drives the volume effect, we examine whether brokerage trading volume follows analysts who change brokerage houses. If so, the analyst, rather than other factors, drives the brokerage share of volume effects. It is more likely that brokerage houses consider trading volume in their hiring decisions, and it is more likely that analysts will thus be concerned with generating volume, if analysts are able to generate similar volume after a brokerage house moves.

We limit our analysis to analysts who moved between brokerage houses within our sample between 2012 and 2015. We require that analysts spend at least one year in each of the brokerages and they cover at least one firm that is the same in both brokerage houses. We identify 58 analysts who moved between brokerages within our sample. Among these analysts, 45 (35) covered at least

3 (5) of the same firms in both brokerage houses. We then estimate the following regression:

Med. Volume Share New Broker ${ }_{b j t}=a_{0}+a_{1}$ Med. Volume Share Analyst $t_{i t-1}+a_{2}$ Med. Volume

$$
\text { Share New Broker } i_{i j t-1}+e_{b j t} \text {, }
$$

where Med. Volume Share $i j t$ is the median Volume Share from the analyst's research dates in a given year $t$ covering firm $j$ after the move to the new brokerage house $b$, capturing the median trading volume that the analyst generates throughout the calendar year. The variable Med. Volume 
Share Analyst $t_{i j t-1}$ is the analyst Volume Share covering firm $j$ in year $t-1$ prior to the move to the new brokerage house. The variable Med. Volume Share New Broker bjt-1 $_{\text {is }}$ is Volume Share of the new brokerage covering firm $j$ in year $t-1$ before the analyst's move.

The results are presented in Table 4. Column 1 presents the results for the full sample. Column 2 (3) displays results when the analyst forecasted a minimum of 3 (5) of the same firms at both the old brokerage house and the new brokerage house. Our variable of interest, Med. Volume Share Analystit-1, is positively and significantly related to Med. Volume Share $e_{i t}$ in each sample (coefficients between 0.120 and $0.147, p$-value $<0.05$ ). ${ }^{29}$ The magnitude ranges from $15 \%$ to $18 \%$ of the effect of the brokerage house trading volume in the previous year. This suggests that the new analyst causes an economically significant shift in broker volume share. These results suggest that analysts have a causal impact on the share of trading volume, and brokerage houses are likely to consider trading volume generation to be a transferrable analyst skill.

\subsection{Analyst Career Concerns}

The results thus far suggest that analysts have incentives to increase optimism and accuracy if they aim to increase trading volume to generate trading commissions for their brokerage houses. However, it is not clear whether analysts are rewarded for generating volume. While anecdotal and survey evidence suggests that analysts are compensated based partly on generating volume (see the discussion in Section 2.1), there is no large-sample empirical evidence regarding the effect of generating volume on analysts' compensation or careers.

\footnotetext{
${ }^{29}$ The results presented in Table 4 are robust to estimation using a fractional logit model instead of ordinary least squares model.
} 
To examine this issue, we focus on analysts' career moves. We employ a methodology similar to Hong and Kubik (2003) and examine whether an analyst's moves across brokerage houses of varying statures are predicted by prior-year performance. Since our sample focuses on the largest brokerage houses and thus captures analysts who are already in strong positions, we focus on downwards career changes. In particular, we test whether there is a negative relation between the trading volume a given analyst generates and the likelihood that the analyst is demoted to a smaller brokerage house. We model analysts' demotion from their employers using the following analyst-year logistic regression:

$$
\operatorname{Pr}\left(\text { Demotion }_{i t+1}\right)=d_{0}+d_{1} \text { Med Volume Share }{ }_{i t}+\text { Controls }+e_{i t},
$$

where we use two different measures for Demotion. Consistent with Hong and Kubik (2003), we use brokerage house size, measured by the number of analysts it employs, as a proxy for prestige. The first measure, Demote1_NextYear, is a dummy variable that takes the value of 1 if, in the following year, the analyst moves to a brokerage house that is smaller than the one she is currently employed by, and takes the value of 0 otherwise. The second measure, Demote2_NextYear takes the value of 1 if the analyst moves from one of the largest brokerage houses (i.e., a brokerage house that employs more than 25 analysts) to one of the smallest brokerage houses (i.e., one that employs fewer than 25 analysts), and takes the value of 0 otherwise. We estimate the model both with and without controls for other dimensions of analyst performance that may affect their career moves, including forecast accuracy, herding, and optimism. ${ }^{30}$

\footnotetext{
${ }^{30} \mathrm{We}$ observe a rate of demotions similar to Hong and Kubik (2003). In their data, roughly $1.5 \%$ of analyst-years include a move from a high-status to a low-status brokerage house (see Hong and Kubik, 2003, Table III, p. 321). In our sample, we find that $2.45 \%$ of analyst-years include a demotion to a smaller brokerage house, while $1.02 \%$ of the eligible analyst-years include a demotion from a "large" to a "small" brokerage house.
} 
Table 5 presents the results of this analysis. We find that the volume share that the analyst creates is significantly and negatively associated with analyst demotions in all specifications. If an analyst generates more trading volume with her research, she is less likely to move to a lowerstatus brokerage house in the following year. This remains true using either measure of demotion and with or without controls for forecast and analyst quality and optimism. ${ }^{31}$ This creates a clear incentive, above and beyond any compensation related to trading commissions, for analysts to act strategically to increase trading volume.

\subsection{Strategic bias}

The results described in Sections 4.1 and 4.2 suggest that forecast optimism and accuracy creates trading volume, and the results reported in Section 4.3 indicate that analysts have an incentive to generate volume. In this section, we test whether analysts strategically bias their forecasts and/or strategically modify their accuracy with the goal of generating trading volume. If an analyst is more (less) successful in generating trading volume with more optimistic forecasts, then she should be more (less) likely to issue optimistically biased forecasts in the future to generate trading volume. Similarly, if an analyst is more (less) successful in generating trading volume with more accurate forecasts, then she should be more (less) likely to engage in additional effort to issue more accurate forecasts. We use Forecast Bias (Current Accuracy) as the dependent

\footnotetext{
${ }^{31}$ Hong and Kubik (2003) find that bottom $10 \%$ relative forecast accuracy is positively (negatively) predictive of analysts moving to a lower-status (higher-status) brokerage house. Groysberg, Healy, and Maber (2011) find that analysts who move from the high-status investment bank they examine to a lower-status bank or exit $\mathrm{I} / \mathrm{B} / \mathrm{E} / \mathrm{S}$ had lower prior-year forecast accuracy. While the coefficient on Med. Current Accuracy in Table 6 is insignificant, we find similar results to Hong and Kubik (2003) and Groysberg, Healy, and Maber (2011) under certain specificationse.g., raking analysts over a wider time period, such as $[-360,-90]$ or $[-360,-30]$. Thus, in our sample, the relation between analyst forecast accuracy and demotion is sensitive to the definition of forecast accuracy used. The coefficient on Med. Analyst Volume remains positive and statistically significant at the 5\% level or better in all such variations.
} 
variable, and we examine whether forecast bias (accuracy) in one year is related to the analystspecific optimism (accuracy)-volume sensitivity from the prior year, while controlling for analystspecific accuracy (optimism)-volume sensitivity from the prior year.

We limit our analysis to analysts who have a minimum of two years of data within our sample between the years 2011 and 2015. We also require that the analyst issued at least 30 forecasts in a given year to all firms she covered. This restriction allows for a more reliable estimate in the first stage, with a minimum of 30 observations for each regression. In the first stage, we estimate the following regressions for each analyst-year pair:

$$
\text { Volume Share }_{i j t}=a_{0}+a_{1} \text { Forecast Bias }_{i j t}+a_{2} \text { Current Accuracy } y_{i j t}+e_{i j t} .
$$

The first stage measures how much trading volume each analyst was able to create using forecast bias and forecast accuracy. In the second stage, we use the analyst-year $\hat{a}_{1}$ and $\hat{a}_{2}$ coefficients estimated in the first stage, and we test whether analysts who have experienced optimism (accuracy) yielding higher trading volume are more optimistic (accurate) in the subsequent year. Conversely, we test whether analysts who have experienced optimism (accuracy) failing to generate trading volume are less optimistic (accurate). The second stage is estimated using the following pooled regression:

$$
\text { Forecast Bias (Accuracy) })_{i j t+1}=b_{0}+b_{1} * \hat{a}_{1 i t}+b_{2} * \hat{a}_{2 i t}+e_{i j t+1} \text {. }
$$

A significantly positive coefficient on $b_{l}$ indicates that the analyst is strategically updating optimistic bias - becoming more (less) optimistic if optimism has been more (less) successful in generating volume in the prior year. A significantly positive coefficient on $b_{2}$ has a similar implication for accuracy. The results of the second stage regression are reported in Table 6 . The results in Panel A (B) examine whether forecast bias (accuracy) in one year is related to the analystspecific optimism (accuracy)-volume sensitivity from the prior year. Column 1 presents results in 
which we limit the sample in the first stage to analyst-years in which the analyst issued at least 30 forecasts. In Panel A, we can see that the coefficient on our variable of interest, $\hat{a}_{1 i t}$, is positive (0.001) and statistically significant at the 5\% level in Column 1 . Columns $2-4$ present the results when we limit the sample in the first stage to analyst-years in which the analyst issued at least 50100 forecasts. These more stringent restrictions serve two purposes. First, they increase the reliability of the estimation of the analysis. Second, they increase the likelihood that the analyst faces a large enough sample to learn and thus adjust behavior. Thus, both econometrically and conceptually, we expect a greater capacity to detect strategic updating behavior when restricting our sample to analyst-years that contain more forecasts. The results are consistent with this. Panel A, Column 4, shows the strongest effect. The coefficient on $\hat{a}_{1 i t}$ is equal to 0.01 and is statistically significant at the $1 \%$ level. The results show that optimism is increasing in prior-year optimismvolume sensitivity, suggesting that analysts strategically update their forecast optimism. ${ }^{32}$

The results from the analysis of the effects of past accuracy creating trading volume on future accuracy are presented in Panel B. The coefficient of our variable of interest, $\hat{a}_{2 i t}$, is not statistically significant across any of the specifications. These results suggest that analysts are unable or unwilling to create more accurate forecasts even when more accurate forecasts in the prior year created trading volume. This is consistent with it requiring significantly more resources, time, effort, and access to management to increase accuracy than to increase optimism. It may be that analysts are unable to update accuracy significantly in a single year's time, or it may be that the volume-related reward is insufficient to incentivize such an update.

\footnotetext{
${ }^{32}$ Results presented in Panel A (B) control for prior-year volume-accuracy (volume-optimism) sensitivity. However volume-optimism and volume-accuracy sensitivity are negatively correlated at the analyst-year level - analysts who experience higher rewards to optimism typically experience lower rewards to accuracy. To ensure that this negative correlation is not driving results, we estimate the model without the inclusion of these controls. Results are similar.
} 


\section{Conclusion}

We examine the potential conflict of interest derived from one of the primary funding mechanisms for modern sell-side security analysis: brokerage trading commissions. We find that optimism in earnings forecasts is associated with a higher brokerage share of trading volume, even after controlling for forecast and analyst quality, recommendations, and target prices. This statistically and economically significant association is consistent with an analyst's incentive to optimistically bias her research, which is also consistent with the theoretical predictions of Beyer and Guttman (2011). However, we also find that forecast and analyst quality are associated with a larger brokerage share of trading volume, with similar economic magnitudes for the effects of optimism and quality.

We address whether analysts drive the increased brokerage share of volume by examining analyst moves across brokerage houses. We find that when an analyst changes brokerage houses, the new brokerage house earns a brokerage trading volume that is consistent with the analyst having a causal effect on the broker's share of volume.

Furthermore, we examine analysts' incentives to generate volume by examining their career progress. We find that analysts who generate more trading volume for their brokerage houses are less likely to move to a lower-status firm in the subsequent year. Failure to generate volume increases the likelihood of demotion to a lower-status brokerage house. Thus, analysts are incentivized to generate trading volume even if they are not directly compensated for it.

Finally, we examine whether analysts strategically update their optimism and accuracy in response to volume-generation incentives. We find that analysts become more (less) optimistic if their prior-year experience demonstrated that optimism is more (less) successful at generating 
volume, consistent with strategic updating of optimism. However we find no evidence for strategic updating of accuracy.

Taken together, our evidence points to a conflict of interest that can at least partially explain analysts' optimistic earnings forecasts. This paper is relevant for researchers in accounting, finance, and economics, as our findings speak to the incentives of sell-side analysts whose research impacts stock prices, investor behavior, and the information environment of firms. Our results also speak to a more general issue: the potential disciplining effect of incentives generated by customer behavior. The link between analyst research and trading volume is not automatic; it is decided by brokerage house customers (i.e., investors). Certain features of these customers (in this case, risk aversion and short sale constraints) can lead to incentives towards bias. However, customers also have the power to reward quality and thus incentivize analysts to produce valuable research. This tension between incentives towards bias and incentives towards quality will likely be found in other settings in which customers choose how to reward service providers.

Last, these results have relevance for current policy questions in the era of MiFID II. We can measure only the direct trading volume around an analyst's research; therefore, the full economic magnitude of commissions-related incentives is likely even larger than the measurement we find in this study. Our findings also lend some credence to institutional investors' claims that commissions currently serve as an incentive for brokerage houses to produce high-quality research, given the results for our forecast and analyst quality variables, however this incentive may not be sufficient to drive analyst behavior. The impact of MiFID II unbundling on incentives towards optimism and quality will be an important question for future research. 


\section{References}

Amiram, D., E. Owens, and O. Rozenbaum. 2016. Do information releases increase or decrease information asymmetry? New evidence from analyst forecast announcements. Journal of Accounting and Economics 62: 121-138.

Baik, B., and H. Yi. 2007. Are affiliated analysts more likely than unaffiliated analysts to provide EPS forecasts that management can meet or beat? Working Paper, Seoul National University and The University of Oklahoma.

Barber, B. M., R. Lehavy, and B. Trueman. 2007. Comparing the stock recommendation performance of investment banks and independent research firms. Journal of Financial Economics 85: 490-517.

Beyer, A., D. A. Coehn, T. Z. Lys, and B. R. Walther. 2010. The financial reporting environment: Review of the recent literature. Journal of Accounting and Economics 50: 296-343.

Beyer, A., and I. Guttman. 2011. The effect of trading volume on analysts' forecast bias. The Accounting Review 86 (2): 451-481.

Bradshaw, M. 2011. Analysts' forecasts: What do we know after decades of work? Working Paper, Boston College.

Bradshaw, M., Y. Ertimur, and P. O'Brien. 2017. Financial analysts and their contribution to wellfunctioning capital markets. Foundations and Trends in Accounting 11 (3): 119-191.

Brown, L. D., A. C. Call, M. B. Clement, and N. Y. Sharp. 2015. Inside the "black box" of sellside financial analysts. Journal of Accounting Research 53 (1): 1-47.

Call, A. C., N. Y. Sharp, and P. A. Wong. 2019. Changes in analysts' stock recommendations following regulatory action against their brokerage. Review of Accounting Studies forthcoming.

Chen, X., Q. Cheng, and K. Lo. 2010. On the relationship between analyst reports and corporate disclosures: Exploring the roles of information discovery and interpretation. Journal of Accounting and Economics 49: 206-226.

Clement, M. B., and S. Y. Tse. 2003. Do investors respond to analysts' forecast revisions as if forecast accuracy is all that matters? The Accounting Review 78 (1): 227-249.

Clement, M. B., and S. Y. Tse. 2005. Financial analyst characteristics and herding behavior in forecasting. Journal of Finance 60 (1): 307-341.

Corwin, S. A., S. A. Larocque, and M. A. Stegemoller. 2017. Investment banking relationships and analyst affiliation bias: The impact of the global settlement on sanctioned and nonsanctioned banks. Journal of Financial Economics 124 (3): 614-631. 
Cowen, A., B. Groysberg, and P. Healy. 2006. Which types of analyst firms are more optimistic? Journal of Accounting and Economics 41, 119-146.

Dechow, P. M., A. P. Hutton, and R. G. Sloan. 2000. The relation between analysts' forecasts of long-term earnings growth and stock price performance following equity offerings. Contemporary Accounting Research 17 (1): 1-32.

Dugar, A., and S. Nathan. 1995. The effects of investment banking relationships on financial analysts' earnings forecasts and investment recommendations. Contemporary Accounting Research 12 (1): 131-160.

Engler, H. April 21, 2017. US firms in uncharted waters over looming EU requirement to unbundle research. Reuters. Available at https://www.reuters.com/article/bc-finreg-us-eurequirements/u-s-firms-in-uncharted-waters-over-looming-eu-requirement-to-unbundleresearch-idUSKBN17N1R1.

Ertimur, Y., V. Muslu, and F. Zhang. 2011. Why are recommendations optimistic? Evidence from analysts' coverage initiations. Review of Accounting Studies 16: 679-718.

Financial Conduct Authority. 2017. Markets in Financial Instruments Directive II Implementation - Policy Statement II. Available at: https://www.fca.org.uk/publication/policy/ps1714.pdf.

Firth, M., C. Lin, P. Liu, and Y. Xuan. 2013. The client is king: Do mutual fund relationships bias analyst recommendations? Journal of Accounting Research 51 (1): 165-200.

Fischer, P. E., and P. C. Stocken. 2010. Analyst information acquisition and communication. The Accounting Review 85 (6): 1985-2009.

Grant, A., Jarnecic, E., and M. Su. 2015. Asymmetric effects of sell-side analyst optimism and broker market share by clientele. Journal of Financial Markets 24: 49-65.

Gleason, C. A., and C. M. C. Lee. 2003. Analyst forecast revisions and market price discovery. The Accounting Review 78 (1): 193-225.

Greenwich Associates. 2015. Broker vote mechanics: Valuating sell-side research and compensating brokers.

Groysberg, B., and P. M. Healy. 2013. Wall Street Research, Past, Present, and Future. Stanford University Press.

Groysberg, B., P. M. Healy, and D. A. Maber. 2011. What drives sell-side analyst compensation at high-status investment banks? Journal of Accounting Research 49 (4): 969-999.

Gu, Z., Z. Li, and Y. G. Yang. 2013. Monitors or Predators: The Influence of Institutional Investors on Sell-Side Analysts. The Accounting Review 88 (1): 137-169. 
Hayes, R. M. 1998. The impact of trading commission incentives on analysts' stock coverage decisions and earnings forecasts. Journal of Accounting Research 36 (2): 299-320.

Hong, H. and J. Kubik. 2003. Analyzing the analysts: career concerns and biased earnings forecasts. The Journal of Finance 58(1), 313-351.

Hovakimian, A., and E. Saenyasiri. 2014. US Analyst regulation and the earnings forecast bias around the world. European Financial Management 20 (3): 435-461.

Huang, A., R. Lehavy, A. Zang, and R. Zheng. 2016. Analyst information discovery and interpretation roles: A topic modeling approach. Management Science, forthcoming.

Irvine, P.J.A. 2001. Do analysts generate trade for their firms? Evidence from the Toronto stock exchange. Journal of Accounting and Economics 30: 209-226.

Irvine, P.J. 2004. Analysts' forecasts and brokerage-firm trading. The Accounting Review 79 (1): 125-149.

Jackson, A. R. 2005. Trade generation, reputation, and sell-side analysts. The Journal of Finance 60 (2): 673-717.

Juergens, J. L., and L. Lindsey. 2009. Getting out early: An analysis of market making activity at the recommending analyst's firm. The Journal of Finance 64 (5): 2327-2359.

Kadan, O., L. Madureira, R. Wang, and T. Zach. 2009. Conflicts of interest and stock recommendations: The effects of the global settlement and related regulations. The Review of Financial Studies 22 (10): 4189-4217.

Kothari, S. P., E. So, and R. Verdi. 2016. Analysts' forecasts and asset pricing: A survey. Annual Review of Financial Economics 8: 197-219.

Leone, A., and J. S. Wu. 2007. What does it take to become a superstar? Evidence from institutional investor rankings of financial analysts. Working Paper, Penn State University and University of Rochester.

Levine, M. 2015. Banks want analysts to earn their keep. Bloomberg View, September 22, 2015. Available at: https://www.bloomberg.com/view/articles/2015-09-22/banks-want-analyststo-earn-their-keep.

Li, K. K., and H. You. 2015. What is the value of sell-side analysts? Evidence from coverage initiations and terminations. Journal of Accounting and Economics 60: 141-160.

Lin, H., and M. F. McNichols. 1998. Underwriting relationships, analysts' earnings forecasts and investment recommendations. Journal of Accounting and Economics 25: 101-127.

Malmendier, U., and D. Shanthikumar. Are small investors naïve about incentives? Journal of Financial Economics 85: 457-489. 
Malmendier, U., and D. Shanthikumar. 2014. Do security analysts speak in two tongues? Review of Financial Studies 27 (5): 1287-1322.

Michaely, R., and K. L. Womack. 1999. Conflict of interest and the credibility of underwriter analyst recommendations. The Review of Financial Studies 12 (4): 653-686.

Mikhail, M. B., B. R. Walther, and R. H. Willis. 2007. When security analysts talk, who listens? The Accounting Review 82 (5): 1227-1253.

Niehaus, G., and D. Zhang. The impact of sell-side analyst research coverage on an affiliated broker's market share of trading volume. Journal of Banking and Finance 34: 776-787.

O'Brien, P. C. 1988. Analysts' forecasts as earnings expectations. Journal of Accounting and Economics 10: 53-83.

O’Brien, P. C., M. F. McNichols, and H. Lin. 2005. Analyst impartiality and investment banking relationships. Journal of Accounting Research 43 (4): 623-650.

Richardson, S., S. H. Teoh, and P. D. Wysocki. 2004. The walk-down to beatable analyst forecasts: The role of equity issuance and insider trading incentives. Contemporary Accounting Research 21 (4): 885-924.

Securities and Exchange Commission (SEC). 2019. SEC Announces Extension of Temporary Measure to Facilitate Cross-Border Implementation of the European Union's MiFID II's Research Provisions. Accessed on November 6, 2019: 


\section{Appendix A. Variable Definitions}

Volume Share Variables

Volume Share

The sum of the share volume traded in firm $j$ over the $[-1,5]$ tradingday window by brokerage $k$ divided by the sum of the total number of shares traded in firm $j$ over the same $[-1,5]$ trading-day window, multiplied by 100 . [(sum daily brokerage volume over $[-1,5] \div$ sum total volume over $[-1,5]) \times 100]$. Day 0 is the day the analyst issued her research.

Med. Volume Share Analyst

The median Volume Share (as defined above) for analyst $i$ in year $t$ covering firm $j$.

Med. Volume Share New Broker

The median Volume Share (as defined above) for broker $b$ in year $t$ covering firm $j$.

Optimism Variables

Forecast Bias

(EPS Forecast $i, j, t-$ EPS Actual $j, t) \div$ Price $_{j, t}$; EPS Forecast $i, j, t$ is analyst $i$ 's forecast at time $t$ for company $j$. This forecast is then compared to actual EPS. This difference is divided by the price per share for company $j$ at the end of fiscal year $t$. The measure is ranked into 10 deciles between 0 and 1 for all analysts covering firm $j$ in year $t$.

Buy

Indicator variable that receives the value of 1 if the analyst issued a strong buy or a buy recommendation, and 0 otherwise.

Sell

Indicator variable that receives the value of 1 if the analyst issued a strong sell or a sell recommendation, and 0 otherwise.

Target Optimism

Price target of analyst $i$ for company $j$ divided by the prior trading day's price. The measure is ranked into 10 deciles between 0 and 1 for all analysts covering firm $j$ in year $t$.

Ind_Forecast

Indicator variable that receives the value of 1 if analyst $i$ issued an EPS forecast for company $j$, and 0 otherwise.

Ind_Rec

Indicator variable that receives the value of 1 if analyst $i$ issued a recommendation for company $j$, and 0 otherwise.

Ind_Target

Indicator variable that receives the value of 1 if analyst $i$ issued a target price for company $j$, and 0 otherwise. 
Current Accuracy

Herding

First

Forecast Age

Analyst Quality Variables

Prior Accuracy

\# Forecasts
\# Years Followed $\mid\left(\right.$ EPS Forecast $_{i, j, t}-$ EPS Actual $\left._{j, t}\right) \mid \div$ Price $_{j, t}$; The measure is ranked separately for three different time horizons: [0, 90], [91, 180], and more than 180 days until the earnings announcement. Following Hong and Kubik (2003), the measure is divided by 100, to range between 0 and 1 as follows: $\{100-[(\operatorname{rank}-1) \div($ number of analysts -1$)] \times$ $100\} \div 100$. The measure uses all forecasts made for firm $j$ in year $t$ in each of the three different time horizons.

Indicator variable that receives the value of 1 for forecasts that are between the analyst's own prior forecast and the consensus forecast (the consensus is calculated as the median outstanding forecast for company $j$ made within 90 days from analyst $i$ forecast), and 0 otherwise.

Indicator variable that receives the value of 1 for the first EPS forecast made by analyst $i$ for company $j$ in year $t$, and 0 otherwise.

The number of days the EPS forecast/target/recommendation was made before the closest earnings announcement date, divided by 365 .
Calculated similarly to Current Accuracy, but using the latest forecast made in the $[-90,0]$ day window before the earnings announcement for year $t-1$.

The number of forecasts issued by analyst $i$ following firm $j$ in year $t^{-1}$ minus the minimum number of forecasts issued by analysts who follow firm $j$ in year $t-1$, with this difference scaled by the range of the number of forecasts issued by analysts who follow firm $j$ in year $t-1$.

A measure of analyst $i$ 's firm-specific experience. It is calculated as the number of years of firm-specific experience for analyst $i$ following firm $j$ in year $t-1$, minus the minimum number of years of firm-specific experience for analysts who follow firm $j$ in year $t-1$, with this difference scaled by the range of years of firm-specific experience for analysts who follow firm $j$ in year $t-1$. 
\# Firms Followed A measure of the number of companies that analyst $i$ follows in year $t-1$. It is calculated as the number of companies followed by analyst $i$ following firm $j$ in year $t-1$, minus the minimum number of companies followed by analysts who follow firm $j$ in year $t-1$, with this difference scaled by the range in the number of companies followed by the analysts who follow firm $j$ in year $t-1$.

\# Analysts Following The number of analysts who cover firm $j$ at time $t-1$.

Brokerage Statistics

Sum Volume

The sum of the daily volume of shares traded by brokerage $k$ in year $t$, in billions.

Brokerage Size

Number of analysts employed by brokerage $k$ in year $t$.

Percent of

The ratio of the total dollar amount of US equity underwriting deals a Underwriting brokerage participated in year $t$ to the total dollar volume of US equity offerings (as reported by Bloomberg) in year $t$, multiplied by 100 .

Shares per Revenue

The ratio of the total number of shares traded by a brokerage divided Dollar by the total net revenue of the brokerage in year $t$.

Analyst Demotion Variables

Demote1_Next Year

Indicator variable equal to 1 if the analyst moved from a larger to a smaller brokerage in the following year, and 0 otherwise.

Demote2_Next Year

Indicator variable equal to 1 if the analyst moved from a brokerage with greater than or equal to 25 analysts to one with less than 25 analysts in a given year, and 0 otherwise. 
Table 1. Brokerage Descriptive Statistics

Panel A. Brokerage-specific trading volume

\begin{tabular}{|c|c|c|c|c|c|c|c|}
\hline \multirow[b]{2}{*}{ Brokerage } & \multicolumn{7}{|c|}{ Total Share Volume Traded (in millions) } \\
\hline & 2011 & 2012 & 2013 & 2014 & 2015 & Mean & Std. Dev. \\
\hline 1 & $3,518.96$ & $3,968.92$ & $3,960.81$ & $4,062.82$ & $3,302.94$ & $3,762.89$ & 332.65 \\
\hline 2 & $3,194.20$ & $2,292.88$ & $3,026.30$ & $3,366.51$ & $2,380.38$ & $2,852.05$ & 486.63 \\
\hline 3 & $3,136.17$ & $2,903.73$ & $2,801.48$ & $2,618.73$ & $2,457.70$ & $2,783.56$ & 260.98 \\
\hline 4 & $2,543.33$ & $2,251.41$ & $2,280.61$ & $2,021.63$ & $1,880.43$ & $2,195.48$ & 255.37 \\
\hline 5 & $2,059.29$ & $2,518.29$ & $1,625.95$ & $1,322.08$ & 950.45 & $1,695.21$ & 614.15 \\
\hline 6 & $1,545.63$ & $1,958.61$ & $1,810.29$ & $1,669.09$ & $1,643.30$ & $1,725.38$ & 161.11 \\
\hline 7 & $1,070.93$ & $1,902.23$ & $1,320.79$ & $1,413.80$ & $2,024.77$ & $1,546.50$ & 403.11 \\
\hline 8 & $2,035.32$ & $1,531.46$ & $1,365.64$ & $1,223.04$ & 995.52 & $1,430.19$ & 391.30 \\
\hline 9 & $1,370.62$ & $1,190.26$ & $1,209.46$ & $1,124.09$ & $1,124.55$ & $1,203.79$ & 100.84 \\
\hline 10 & 405.86 & 439.87 & 336.93 & 325.04 & 319.26 & 365.39 & 54.20 \\
\hline 11 & 215.69 & 261.43 & 319.52 & 338.18 & 475.80 & 322.13 & 98.61 \\
\hline 12 & 93.01 & 108.92 & 155.21 & 152.00 & 140.64 & 129.96 & 27.59 \\
\hline 13 & 169.42 & 181.46 & 206.23 & 117.84 & 100.16 & 155.02 & 44.50 \\
\hline 14 & 101.42 & 98.67 & 120.17 & 85.29 & 80.20 & 97.15 & 15.64 \\
\hline 15 & 66.55 & 101.58 & 121.39 & 94.14 & 84.90 & 93.71 & 20.27 \\
\hline 16 & 71.33 & 126.03 & 111.57 & 103.16 & 60.61 & 94.54 & 27.59 \\
\hline 17 & 5.49 & 9.46 & 3.69 & 79.60 & 90.95 & 37.84 & 43.54 \\
\hline 18 & 2.78 & 3.13 & 2.80 & 2.60 & 1.49 & 2.56 & 0.63 \\
\hline
\end{tabular}

Panel A displays the total number of shares traded by each brokerage of all 1,436 sample firms in each year in the sample period, as well as the mean and standard deviation by brokerage. All amounts are in millions of shares. 
Table 1. Brokerage Descriptive Statistics (Continued)

Panel B. Number of analysts by brokerage

\begin{tabular}{|c|c|c|c|c|c|c|c|}
\hline \multirow[b]{2}{*}{ Brokerage } & \multicolumn{6}{|c|}{ Brokerage Size (\# of analysts) } & \multirow{2}{*}{$\begin{array}{l}\text { Average \# of Stocks } \\
\text { Followed by Analysts } \\
\text { at Each Brokerage }\end{array}$} \\
\hline & 2011 & 2012 & 2013 & 2014 & 2015 & Mean & \\
\hline 1 & 233 & 232 & 243 & 241 & 231 & 236 & 6 \\
\hline 2 & 107 & 112 & 136 & 169 & 169 & 139 & 8 \\
\hline 3 & 125 & 126 & 96 & 79 & 78 & 101 & 7 \\
\hline 4 & 129 & 117 & 114 & 118 & 116 & 119 & 10 \\
\hline 5 & 93 & 90 & 85 & 90 & 82 & 88 & 12 \\
\hline 6 & 111 & 105 & 103 & 117 & 115 & 110 & 10 \\
\hline 7 & 122 & 117 & 145 & 199 & 187 & 154 & 9 \\
\hline 8 & 78 & 91 & 91 & 93 & 92 & 89 & 12 \\
\hline 9 & 116 & 110 & 103 & 112 & 178 & 124 & 9 \\
\hline 10 & 92 & 95 & 100 & 110 & 123 & 104 & 10 \\
\hline 11 & 100 & 81 & 90 & 117 & 133 & 104 & 10 \\
\hline 12 & 64 & 68 & 70 & 76 & 83 & 72 & 14 \\
\hline 13 & 88 & 103 & 83 & 78 & 74 & 85 & 13 \\
\hline 14 & 49 & 51 & 50 & 55 & 42 & 49 & 15 \\
\hline 15 & 110 & 134 & 115 & 101 & 99 & 112 & 11 \\
\hline 16 & 44 & 42 & 39 & 41 & 52 & 44 & 17 \\
\hline 17 & 33 & 30 & 43 & 67 & 67 & 48 & 10 \\
\hline 18 & 75 & 85 & 92 & 84 & 59 & 79 & 10 \\
\hline
\end{tabular}

Panel B displays the number of analysts associated with each brokerage as well as the mean number of analysts at each brokerage over the sample period. The last column displays the average number of stocks followed by all analysts at each brokerage house during the sample period. Amounts are extracted from $\mathrm{I} / \mathrm{B} / \mathrm{E} / \mathrm{S}$ and are not restricted to the analysts in our final sample. 
Table 1. Brokerage Descriptive Statistics (Continued)

Panel C. Brokerage Revenue Breakdown

\begin{tabular}{lccccc|c}
\hline & \multicolumn{5}{c}{ Shares Traded per Dollar of Revenue } \\
Brokerage & 2011 & 2012 & 2013 & 2014 & 2015 & Mean \\
\hline 1 & 0.038 & 0.048 & 0.045 & 0.048 & 0.040 & 0.044 \\
2 & 0.114 & 0.087 & 0.104 & 0.127 & 0.099 & 0.106 \\
3 & 0.106 & 0.104 & 0.090 & 0.092 & 0.080 & 0.094 \\
4 & 0.147 & 0.124 & 0.067 & 0.059 & 0.056 & 0.090 \\
5 & 0.050 & 0.074 & 0.040 & 0.037 & 0.027 & 0.046 \\
6 & 0.048 & 0.075 & 0.056 & 0.049 & 0.047 & 0.055 \\
7 & 0.011 & 0.020 & 0.014 & 0.015 & 0.022 & 0.016 \\
8 & 0.064 & 0.050 & 0.041 & 0.037 & 0.029 & 0.044 \\
9 & 0.034 & 0.028 & 0.029 & 0.030 & 0.032 & 0.031 \\
10 & 0.015 & 0.015 & 0.011 & 0.011 & 0.012 & 0.013 \\
11 & 0.084 & 0.085 & 0.108 & 0.113 & 0.192 & 0.116 \\
12 & 0.001 & 0.001 & 0.002 & 0.002 & 0.002 & 0.002 \\
13 & 0.122 & 0.114 & 0.105 & 0.053 & 0.043 & 0.087 \\
14 & 0.110 & 0.103 & 0.112 & 0.071 & 0.062 & 0.092 \\
15 & 0.020 & 0.027 & 0.027 & 0.019 & 0.016 & 0.022 \\
16 & 0.165 & 0.258 & 0.213 & 0.159 & 0.090 & 0.177 \\
17 & 0.006 & 0.005 & 0.000 & 0.001 & 0.000 & 0.003 \\
18 &. &. &. &. &. &. \\
\hline
\end{tabular}

Panel C displays the ratio of shares traded by each brokerage of all 1,436 sample firms in each year in the sample period to yearly total brokerage revenue, as well as the mean by brokerage. No information was found for brokerage 18, as it is private and does not publicly share any revenue data. 
Table 2. Descriptive Statistics

Panel A. Descriptive statistics

\begin{tabular}{|c|c|c|c|c|c|c|c|c|}
\hline Variable & $\mathbf{N}$ & Mean & Std. Dev. & Min & p25 & Median & p75 & Max \\
\hline Volume Share & 179,417 & 5.311 & 5.016 & 0.005 & 1.217 & 4.246 & 7.678 & 25.207 \\
\hline \multicolumn{9}{|l|}{ Optimism } \\
\hline Forecast Bias & 179,417 & 0.502 & 0.312 & 0 & 0.222 & 0.556 & 0.778 & 1 \\
\hline Buy & 179,417 & 0.030 & 0.170 & 0 & 0 & 0 & 0 & 1 \\
\hline Sell & 179,417 & 0.006 & 0.078 & 0 & 0 & 0 & 0 & 1 \\
\hline Target Optimism & 73,913 & 0.503 & 0.305 & 0 & 0.222 & 0.556 & 0.778 & 1 \\
\hline Ind_Rec & 179,417 & 0.067 & 0.251 & 0 & 0 & 0 & 0 & 1 \\
\hline Ind_Target & 179,417 & 0.414 & 0.493 & 0 & 0 & 0 & 1 & 1 \\
\hline \multicolumn{9}{|l|}{ Forecast Quality } \\
\hline Current Accuracy & 179,241 & 0.506 & 0.295 & 0 & 0.25 & 0.506 & 0.761 & 1 \\
\hline Herding & 142,908 & 0.428 & 0.495 & 0 & 0 & 0 & 1 & 1 \\
\hline First & 179,417 & 0.223 & 0.417 & 0 & 0 & 0 & 0 & 1 \\
\hline Forecast Age & 179,417 & 0.551 & 0.292 & 0 & 0.288 & 0.537 & 0.789 & 1.501 \\
\hline \multicolumn{9}{|l|}{ Analyst Quality } \\
\hline Prior Accuracy & 92,249 & 0.513 & 0.307 & 0 & 0.25 & 0.5 & 0.773 & 1 \\
\hline \# Forecasts & 129,611 & 0.540 & 0.287 & 0 & 0.333 & 0.524 & 0.75 & 1 \\
\hline \# Years Followed & 126,443 & 0.385 & 0.336 & 0 & 0.095 & 0.30 & 0.625 & 1 \\
\hline \# Firms Followed & 129,856 & 0.473 & 0.271 & 0 & 0.278 & 0.452 & 0.655 & 1 \\
\hline \# Analysts Following & 177,237 & 21.625 & 9.112 & 1 & 15 & 21 & 27 & 57 \\
\hline \multicolumn{9}{|l|}{ Brokerage House Characteristics } \\
\hline Sum Volume & 179,417 & 1.554 & 1.178 & 0.001 & 0.318 & 1.529 & 2.290 & 4.041 \\
\hline Brokerage Size & 179,417 & 114.098 & 44.864 & 30 & 90 & 107 & 118 & 243 \\
\hline Percent of Underwriting & 179,417 & 6.699 & 4.089 & 0 & 2.181 & 7.993 & 10.132 & 14.014 \\
\hline Shares per Revenue Dollar & 178,885 & 0.062 & 0.045 & 0 & 0.028 & 0.050 & 0.092 & 0.258 \\
\hline Med. Analyst Volume & 179,417 & 4.600 & 3.734 & 0.005 & 1.043 & 4.345 & 6.402 & 25.207 \\
\hline
\end{tabular}


Table 2. Descriptive Statistics (Continued)

Panel B. Correlations

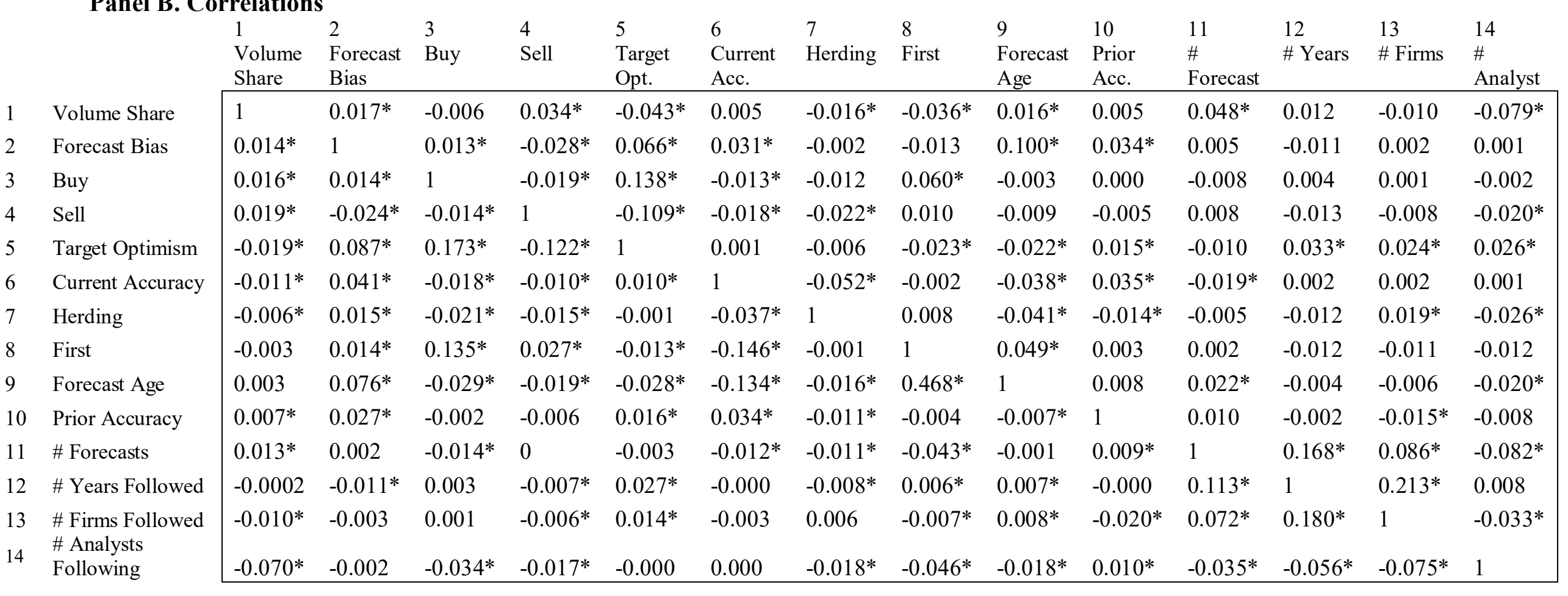

Panel B displays the Pearson (Spearman Rank) correlation coefficients below (above) the diagonal. The asterisks represent correlations significant at the $5 \%$ level or better. Appendix A provides detailed descriptions of each variable. 
Table 3. Effect of Analyst Characteristics on Brokerage Share of Trading Volume

\begin{tabular}{|c|c|c|c|c|}
\hline & $\begin{array}{c}(1) \\
\text { Optimism } \\
\end{array}$ & $\begin{array}{c}(2) \\
\text { Forecast Quality }\end{array}$ & $\begin{array}{c}\text { (3) } \\
\text { Analyst Quality }\end{array}$ & $\begin{array}{c}\text { (4) } \\
\text { All Characteristics } \\
\end{array}$ \\
\hline Forecast Bias & $\begin{array}{c}0.069 * * \\
{[2.32]}\end{array}$ & & & $\begin{array}{c}0.102 * * \\
{[2.05]}\end{array}$ \\
\hline Buyx Ind_Rec & $\begin{array}{c}0.248 * * * \\
{[3.30]}\end{array}$ & & & $\begin{array}{l}0.146 \\
{[0.99]}\end{array}$ \\
\hline Sell $x$ Ind_Rec & $\begin{array}{l}-0.011 \\
{[-0.09]}\end{array}$ & & & $\begin{array}{l}-0.286 \\
{[-1.27]}\end{array}$ \\
\hline Target Optimism x Ind_Target & $\begin{array}{c}0.148 * * * \\
{[2.62]}\end{array}$ & & & $\begin{array}{l}0.082 \\
{[0.92]}\end{array}$ \\
\hline Ind_Rec & $\begin{array}{c}-0.124 * * \\
{[-2.52]}\end{array}$ & & & $\begin{array}{l}0.038 \\
{[0.39]}\end{array}$ \\
\hline Ind_Target & $\begin{array}{l}-0.061^{*} \\
{[-1.67]}\end{array}$ & & & $\begin{array}{l}0.011 \\
{[0.19]}\end{array}$ \\
\hline Current Accuracy & & $\begin{array}{l}0.070^{*} \\
{[1.92]}\end{array}$ & & $\begin{array}{c}0.143 * * \\
{[2.57]}\end{array}$ \\
\hline Herding & & $\begin{array}{l}-0.034^{*} \\
{[-1.69]}\end{array}$ & & $\begin{array}{l}-0.037 \\
{[-1.28]}\end{array}$ \\
\hline First & & $\begin{array}{l}0.031 \\
{[0.60]}\end{array}$ & & $\begin{array}{l}-0.077 \\
{[-0.81]}\end{array}$ \\
\hline Forecast Age & & $\begin{array}{c}0.128 * * * \\
{[3.32]}\end{array}$ & & $\begin{array}{c}0.114^{* * *} \\
{[1.98]}\end{array}$ \\
\hline Prior Accuracy & & & $\begin{array}{c}0.196^{* * *} \\
{[2.73]}\end{array}$ & $\begin{array}{c}0.226 * * * \\
{[3.04]}\end{array}$ \\
\hline \# Forecasts & & & $\begin{array}{l}0.025 \\
{[0.25]}\end{array}$ & $\begin{array}{l}0.032 \\
{[0.31]}\end{array}$ \\
\hline \# Years Followed & & & $\begin{array}{c}0.211^{* *} \\
{[2.49]}\end{array}$ & $\begin{array}{c}0.224 * * \\
{[2.57]}\end{array}$ \\
\hline \# Firms Followed & & & $\begin{array}{l}0.020 \\
{[0.17]}\end{array}$ & $\begin{array}{l}0.029 \\
{[0.23]}\end{array}$ \\
\hline \# Analysts Following & & & $\begin{array}{c}-0.009^{*} \\
{[-1.81]}\end{array}$ & $\begin{array}{c}-0.010^{*} \\
{[-1.93]}\end{array}$ \\
\hline Constant & $\begin{array}{c}11.862 * * * \\
{[122.63]}\end{array}$ & $\begin{array}{c}11.764 * * * \\
{[108.12]}\end{array}$ & $\begin{array}{c}11.671 * * * \\
{[60.48]}\end{array}$ & $\begin{array}{c}11.391 * * * \\
{[54.56]}\end{array}$ \\
\hline Year FE & $\mathrm{Y}$ & $\mathrm{Y}$ & $\mathrm{Y}$ & $\mathrm{Y}$ \\
\hline Broker FE & Y & Y & Y & Y \\
\hline Firm FE & $\mathrm{Y}$ & $\mathrm{Y}$ & $\mathrm{Y}$ & $\mathrm{Y}$ \\
\hline Observations & 179,417 & 142,805 & 72,202 & 60,468 \\
\hline Adj. R-squared & 0.476 & 0.480 & 0.500 & 0.502 \\
\hline
\end{tabular}

Table 3 displays the results of ordinary least squares regressions, relating Volume Share to analyst optimism variables (Column 1), forecast quality variables (Column 2), and analyst quality variables (Column 3), for dates on which an earnings forecast is issued. Column 4 displays the results of all characteristics. Appendix A contains detailed descriptions of the variables. t-statistics are provided in parentheses, with standard errors clustered at the firm level. $*, * *$, and $* * *$ indicate statistical significance at the $10 \%, 5 \%$, and $1 \%$ levels, respectively. 
Table 4. Trading Volume Following an Analyst Move between Brokerage Houses

(1)

All Obs.

$0.139 * *$

[2.61]

Med. Volume Share New Brokerbjt-1

$0.816^{* * *}$

[7.88]

$-0.943$

$[-1.05]$
(2)

(3)

Min 3 Firms

$0.120^{* *}$

[2.45]

$0.814 * * *$

[7.81]

$-0.840$

[-1.00]
$0.147 * *$

[2.46]

$0.840^{* * *}$

[7.52]

$-1.192$

[-1.36]

\begin{tabular}{lccc} 
Year FE & Y & Y & Y \\
Broker FE & Y & Y & Y \\
Observations & 371 & 354 & 319 \\
Adj. R-squared & 0.609 & 0.646 & 0.660 \\
\hline
\end{tabular}

Table 4 examines a sample of analysts' moves between brokerage houses and whether Volume Share follows the analyst from the old brokerage to the new brokerage. The table displays the results of ordinary least squares regressions, relating Volume Share of firm $j$ covered by analyst $i$ in year $t$ to the analyst Volume Share in year $t-1$ before the move and to the Volume Share of the new brokerage $b$ covering firm $j$ in year $t-1$. Column 1 displays the results of all observations. Column 2 (3) displays results when the analyst forecasted a minimum of 3 (5) firms in both the old brokerage and the new brokerage house. Appendix A contains detailed descriptions of the variables. t-statistics are provided in parentheses, with standard errors clustered at the firm level. *,**, and *** indicate statistical significance at the $10 \%, 5 \%$, and $1 \%$ levels, respectively. 
Table 5. Analyst Volume and Subsequent Demotion

\begin{tabular}{|c|c|c|c|c|}
\hline & $\begin{array}{c}(1) \\
\text { Demote1 Next } \\
\text { Year }\end{array}$ & $\begin{array}{c}(2) \\
\text { Demote1 } \\
\text { Next Year }\end{array}$ & $\begin{array}{c}\text { (3) } \\
\text { Demote2 Next } \\
\text { Year }\end{array}$ & $\begin{array}{c}(4) \\
\text { Demote2 Next } \\
\text { Year }\end{array}$ \\
\hline Med. Analyst Volume & $\begin{array}{c}-0.0825^{* *} \\
{[-2.330]}\end{array}$ & $\begin{array}{c}-0.0806^{* *} \\
{[-2.282]}\end{array}$ & $\begin{array}{c}-0.180^{* *} \\
{[-2.088]}\end{array}$ & $\begin{array}{c}-0.180 * * \\
{[-2.028]}\end{array}$ \\
\hline Med. Current Accuracy & & $\begin{array}{c}-0.641 \\
{[-1.155]}\end{array}$ & & $\begin{array}{c}-1.151 \\
{[-1.126]}\end{array}$ \\
\hline Med. \# Forecasts & & $\begin{array}{c}-0.293 \\
{[-0.889]}\end{array}$ & & $\begin{array}{c}-0.868 \\
{[-1.216]}\end{array}$ \\
\hline Avg. Herding & & $\begin{array}{l}-0.587^{*} \\
{[-1.650]}\end{array}$ & & $\begin{array}{c}-0.425 \\
{[-0.695]}\end{array}$ \\
\hline Avg. First & & $\begin{array}{c}0.197 \\
{[0.263]}\end{array}$ & & $\begin{array}{c}-0.671 \\
{[-0.477]}\end{array}$ \\
\hline Med. \# Firms Followed & & $\begin{array}{c}0.0433 \\
{[0.146]}\end{array}$ & & $\begin{array}{c}0.527 \\
{[1.265]}\end{array}$ \\
\hline Med. Forecast Bias & & $\begin{array}{c}0.342 \\
{[0.496]}\end{array}$ & & $\begin{array}{c}0.458 \\
{[0.662]}\end{array}$ \\
\hline Constant & $\begin{array}{c}-2.882 * * * \\
{[-16.66]}\end{array}$ & $\begin{array}{c}-2.433 * * * \\
{[-5.275]}\end{array}$ & $\begin{array}{c}-2.429 * * * \\
{[-4.978]}\end{array}$ & $\begin{array}{c}-1.545 \\
{[-1.282]}\end{array}$ \\
\hline Year FE & Yes & Yes & Yes & Yes \\
\hline Brokerage FE & Yes & Yes & Yes & Yes \\
\hline Observations & 4,705 & 4,705 & 4,375 & 4,375 \\
\hline Pseudo R-squared & 0.0568 & 0.0594 & 0.0642 & 0.0714 \\
\hline
\end{tabular}

Table 5 displays the results of logistic regressions of indicator variables for demotion, Demote1_NextYear and Demote2_NextYear, on Med. Analyst Volume and a set of control variables. Demote1_NextYear takes the value 1 if the analyst moved to a smaller brokerage house in the following year, and 0 otherwise. Demote2_NextYear takes the value 1 if the analyst was in a large brokerage house ( 25 or more analysts) in the current year and moved to a small brokerage house ( 25 or fewer analysts) in the following year. All median or average variables are calculated on an analyst-year basis. Appendix A contains detailed descriptions of the variables. z-statistics are provided in parentheses, with standard errors clustered at the broker level. *, **, and *** indicate statistical significance at the $10 \%, 5 \%$, and $1 \%$ levels, respectively. 
Table 6. The Effect of Analyst Past Success in Creating Trading by Optimism and Accuracy on Analyst Future Optimism and Accuracy

\section{Panel A. Optimism}

(1)

Min of 30 Obs. Min of $50 \mathrm{Obs}$. Min of 800

\begin{tabular}{lcccc}
\hline & & & & \\
$\hat{a}_{1 i t}$ & $0.001^{* *}$ & $0.002^{* *}$ & $0.003^{* *}$ & $0.010^{* * *}$ \\
& {$[2.20]$} & {$[2.19]$} & {$[2.16]$} & {$[4.17]$} \\
$\hat{a}_{2 i t}$ & $0.002 * * *$ & $0.002^{* *}$ & 0.001 & 0.003 \\
& {$[3.39]$} & {$[2.28]$} & {$[0.84]$} & {$[1.32]$} \\
Constant & $0.503^{* * *}$ & $0.503^{* * *}$ & $0.508^{* * *}$ & $0.508^{* * *}$ \\
& {$[525.73]$} & {$[376.01]$} & {$[191.74]$} & {$[137.89]$} \\
& & & & \\
Year FE & $\mathrm{Y}$ & $\mathrm{Y}$ & $\mathrm{Y}$ & $\mathrm{Y}$ \\
Firm FE & $\mathrm{Y}$ & $\mathrm{Y}$ & $\mathrm{Y}$ & $\mathrm{Y}$ \\
Observations & 108,047 & 80,861 & 38,969 & 21,717 \\
Adj. R-squared & 0.000159 & 0.000132 & 0.000256 & 0.00128 \\
\hline
\end{tabular}

\section{Panel B. Accuracy}

(1)

(2)

(3)

(4)

Min of 30 Obs. Min of 50 Obs. Min of 80 Obs. Min of 100 Obs.

\begin{tabular}{lcccc}
$\hat{a}_{1 i t}$ & -0.000 & -0.000 & 0.001 & -0.004 \\
& {$[-0.43]$} & {$[-0.41]$} & {$[0.37]$} & {$[-1.40]$} \\
$\hat{a}_{2 i t}$ & -0.000 & -0.000 & 0.001 & 0.002 \\
& {$[-0.12]$} & {$[-0.04]$} & {$[0.59]$} & {$[0.99]$} \\
Constant & $0.501^{* * *}$ & $0.498^{* * *}$ & $0.498^{* * *}$ & $0.497 * * *$ \\
& {$[321.96]$} & {$[258.01]$} & {$[144.04]$} & {$[104.15]$} \\
& & & & \\
Year FE & $\mathrm{Y}$ & $\mathrm{Y}$ & $\mathrm{Y}$ & $\mathrm{Y}$ \\
Firm FE & $\mathrm{Y}$ & $\mathrm{Y}$ & $\mathrm{Y}$ & $\mathrm{Y}$ \\
Observations & 107,961 & 80,797 & 38,939 & 21,711 \\
Adj. R-squared & 0.000217 & 0.000313 & 0.000421 & 0.000353 \\
\hline
\end{tabular}

Table 6 displays the results of the second stage of a two-stage least squares regression. The first stage tests whether the analyst can create trading volume from optimism and accuracy in their earnings forecasts. The regression is of the form Volume Shar $_{i j t}=a_{0}+a_{1}$ Forecast Bias $_{i j t}+a_{2}$ Current Accuracy $_{i j t}+e_{i j t}$ and is estimated for each analyst-year, yielding an analyst-year specific estimate of $\hat{a}_{1 i t}$ and $\hat{a}_{2 i t}$. We limit the sample to analyst-years for which the number of forecasts available to estimate the first-stage regression is at least 30,50, 80, and 100 in Columns 1,2,3, and 4, respectively. The second stage tests whether the analyst has learned that optimism (accuracy) yields trading volume and becomes more optimistic (accurate) as a result. The results are presented in Panel A (B). The regression is of the form Forecast Bias (Accuracy) $_{i j t+1}=b_{0}+b_{1} * \hat{a}_{1 i t}+b_{2}{ }^{*} \hat{a}_{2 i t}+e_{i j t+1}$, and is estimated across all analysts. t-statistics are provided in parentheses, with standard errors clustered at the firm level. *,**, and *** indicate statistical significance at the $10 \%, 5 \%$, and $1 \%$ levels, respectively. 